\title{
Planning Guide for a Total Market Approach to Increase Access to Family Planning: Toolkit and Glossary
}

Christopher Brady

Laura Weeden

Jane Hutchings

Jerry Parks

Follow this and additional works at: https://knowledgecommons.popcouncil.org/departments_sbsr-rh How does access to this work benefit you? Let us know!

\section{Recommended Citation}

Brady, Christopher, Laura Weeden, Jane Hutchings, and Jerry Parks. 2016. "Planning Guide for a Total Market Approach to Increase Access to Family Planning: Toolkit and Glossary." Seattle, WA: PATH and Washington, DC: The Population Council, The Evidence Project. 


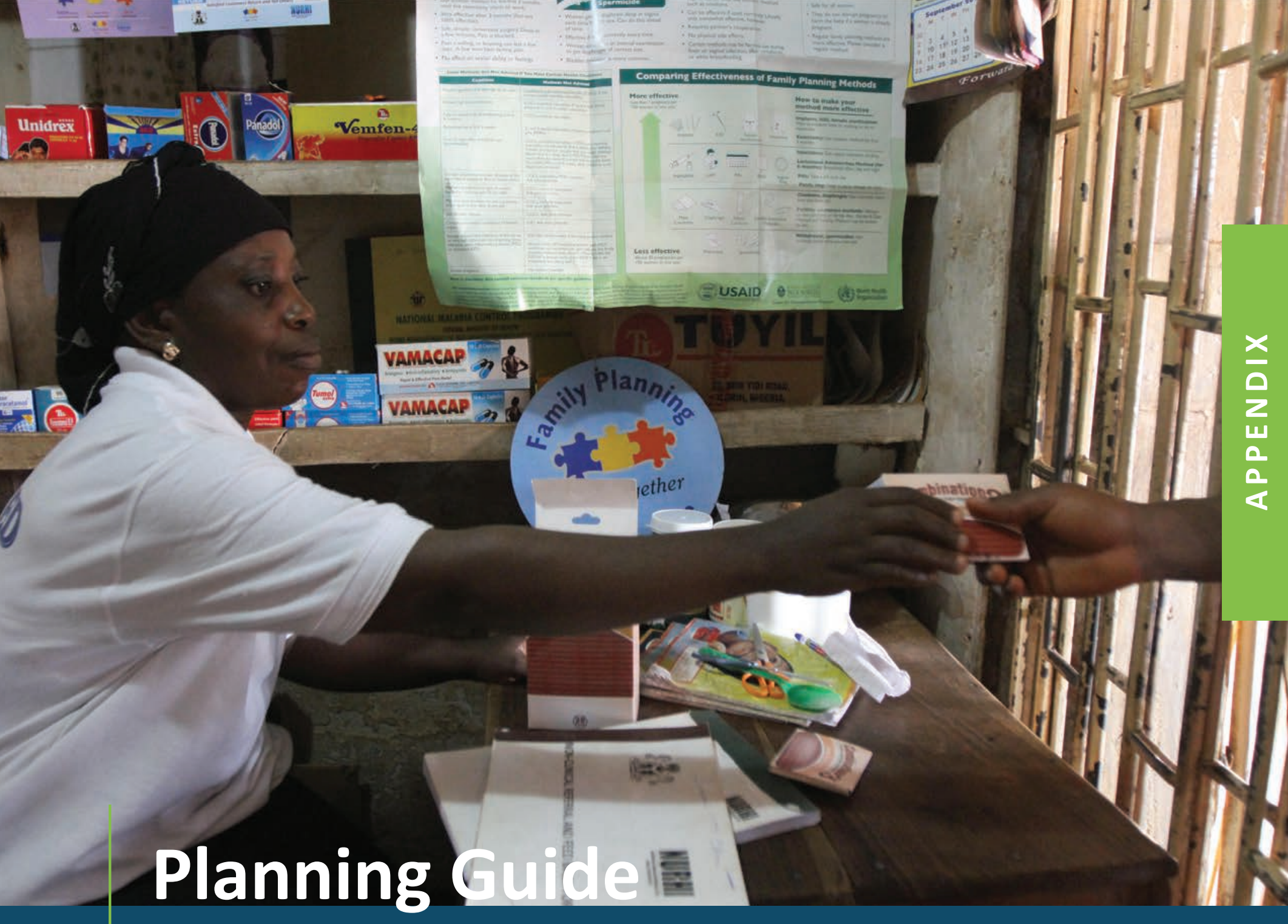

for a Total Market Approach to

Increase Access to Family Planning

Toolkit and Glossary

Authors:

Christopher Brady

Laura Wedeen

Jane Hutchings

Jerry Parks

January 2016

(P) USAID Evidence

$\overbrace{\text { MEASURE }}^{\text {Evaluation }}$

\%०คPTH 


\section{CONTENTS}

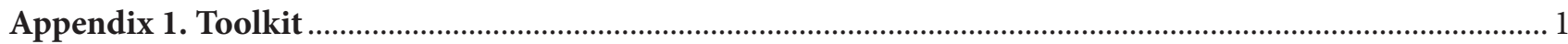

Tool 1: Documents for General Landscaping Desk Review .................................................................................. 1

Tool 2: Considerations When Evaluating TMA-Related Work in Different Country Contexts ......................... 10

Tool 3: Generic TMA Overview_Presentation ................................................................................................. 13

Tool 4: Guidance on the Research Determination Process, Sample Research Protocol on TMA Landscaping, Sample Informed Consent Form, and Sample Generic Stakeholder Interview Guide.......................................................................... 16

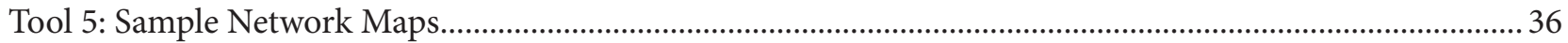

Tool 6: Sample Agenda for Stakeholder Dissemination Meeting and Sample Outline for Breakout Groups ........................................................................................................ 41

Tool 7: How Participating in TMA Work Can Benefit the Commercial Contraceptive

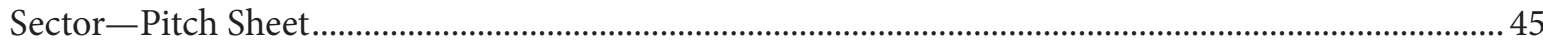

Appendix 2. Glossary 


\section{APPENDIX 1. TOOLKIT}

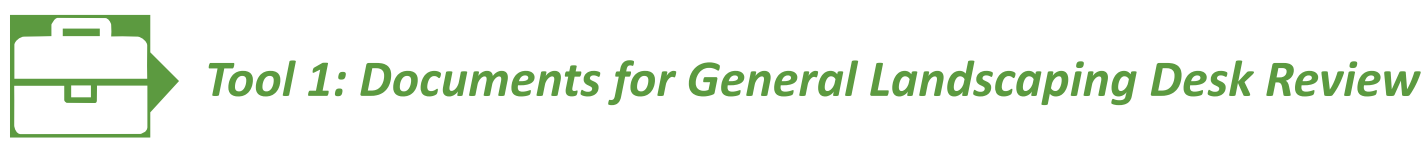

Conducting a desk review is a key step in the landscaping process. A desk review is an activity intended to provide total market approach (TMA) planners with an in-depth understanding of available country-specific literature and other family planning (FP)-related documents. This background can inform strategies for in-country landscaping work as well as identify the most influential stakeholders and coordinating bodies. These individuals will be considered key informants going forward and can help direct the TMA planner to other materials and resources.

Focus areas for a desk review include the following: availability and access to products and services across sectors, including current contraceptive pricing and charging practices; data on contraceptive usage and preferences; and barriers to contraceptive use, financing, and procurement.

The desk review should also highlight key government policies that support or inhibit the private sector, relevant regulatory requirements, tax practices, government FP goals, commitments, and systems; unmet need; and current and planned activities to increase the modern contraceptive prevalence rate, as well as any other issues that are likely to have a bearing on a TMA.

A large percentage of content found may be linked to gray literature such as technical reports, evaluations, working papers, white papers, and other documents that are less accessible through online and published records. Gathering these documents is likely to require deeper searches on organizations' websites as well as direct interaction with key informants/stakeholders in a particular country context.

\subsection{High-level key country development policy references related to family planning}

A good place to begin the desk review is to look at the ministry of health $(\mathrm{MOH})$ website from the country in question to find key country development policy documents related to FP. Bear in mind that important contextual data on the FP situation in a country may not be readily available on the Internet or through disseminated reports and publications. More digging will be required: investigate in-country resources, including the $\mathrm{MOH}$ reproductive health department or health statistics office, management information systems, and donor reports maintained by different organizations. A more comprehensive list of documents that may provide useful insights is included at the end of Tool 1. Key sections of information are identified with a where they appear in the text. Essential documents to focus on include the following:

- National health strategy or plan.

- National health review documents.

- National reproductive health strategy or plan.

- National family planning strategy or plan. 
- Family planning 2020 costed implementation plan.

- Country policies and plans related to decentralization, health financing, and universal health coverage.

- Donor strategies in the health and FP sectors related to FP.

- Strategic plan for the procurement of reproductive health commodity security.

- Annual reports for national reproductive health programs.

- Government organizational charts (organigrams).

Other source documents and resources may include:

- Performance Monitoring and Accountability (PMA) 2020 data.

- Most recent Demographic and Health Survey.

- World Bank data.

- United Nations Population Fund (UNFPA).

- World Health Organization.

- Population Reference Bureau.

- Key social marketing organizations, such as Population Services International and DKT International. Specific documents from these organizations are listed at the end of Tool 1.

\subsection{Questions to guide a desk review}

The questions below are intended to help TMA practitioners guide and frame their desk review. When responding to the questions, it can be helpful to not only answer the question itself, but also think thoroughly about which documents may be useful to help answer the questions posed and what other content the document contains. The process of responding to each question can be as beneficial as answering the question itself. (The key TMA readiness questions found in Tool 2 may also be helpful here.)

\section{Policy and strategy questions to consider:}

- How does the country's political leadership see the health sector's role in its broader development agenda? (Often this can be discerned from the national development plan.) This can provide insights into what the government sees as key priorities going forward.

- What level of human and financial resources has the government committed to strengthen the health sector generally and FP in particular? (What is the percentage of national budget commitments earmarked for supporting the health sector?)

- How will the government finance its national health strategies and plans? To what extent is the government reliant on external funds, and what proportion is earmarked for FP specifically? If possible, this can be broken down further by commodities, health-sector-wide financial support, support for demand-creation activities, and support for supply chain/logistics systems. 
- Are donors likely to be committed to the country for the next five to ten years? What major FP projects being funded by external donors are currently being implemented in country (particularly those that might affect TMA planning and thinking)?

- How does the national health strategy align with total market approach perspectives related to engaging with the private sector?

- Does universal health coverage or another health financing mechanism exist? How is FP incorporated into these policies?

- To what extent does strategic decision-making occur at the national or subnational levels in relation to the provision of FP products and services?

- When will the national health strategy be renewed, and what processes are in place to develop this agenda?

- Which agencies are most closely involved with health strategy development?

- Do strategies and plans include engagement of the private sector?

\section{Family planning questions to consider:}

- What are the government's FP priorities?

- Are efforts to satisfy unmet demand for FP services specifically detailed and costed?

- What mechanisms, if any, are in place to coordinate public- and private-sector efforts?

- What commitments related to FP have been made at the global level (e.g., commitments found in a costed implementation plan)?

-What plans are in place to fulfill those commitments?

- What mechanisms currently exist to coordinate the procurement and distribution efforts of different suppliers, such as international donors, social marketing, or commercial-sector entities?

- Does a contraceptive security committee or similar structure exist?

- Does it carry out joint forecasting and procurement planning?

$\circ$ Who are its members?

- Is there private-sector and commercial representation?

- What initiatives has it taken on/accomplished?

- Who are the most influential stakeholders involved in FP programming?

- What departments, organizations, or units are significant in influencing the FP markets?

- Which individuals within those settings are most influential?

- How do these individuals influence the market in FP?

- Who can most effectively serve as key informants for in-depth interviews during a TMA landscape assessment? 


\subsection{Sample desk research outline and guide}

The outline below provides a suggested format for approaching and writing a desk review during the TMA assessment process. Not all of this information will necessarily be available during the landscaping phase. Capturing as much of this existing data as possible will be useful, but it is important to recognize that further research may be required to fill evidence gaps. Bear in mind that as the landscaping process evolves, it is highly likely that additional information will become available; further information can be integrated into the document over time. Also, the structure of the desk review document can vary depending on the FP environment as well as the availability of information.

\section{Sample desk research outline}

\section{Introduction.}

Provide a summary of your project in the introduction, including goals and funder information. You may also want to include a short summary of the desk review and its purpose.

\section{Social, economic, political, cultural, and demographic context.}

Broadly describe the socioeconomic and political situation (if relevant to the FP environment). This will help understand the broader factors that can contribute to a high total fertility rate or low modern contraceptive prevalence rate, as well as provide background information on existing structures that can shape how a TMA is implemented.

Demographics:

- Population size.

- Population distribution.

- Ethnic makeup.

$\circ$ Age structure.

- Life expectancy (both sexes).

- Geographical distribution (proportion of population living in urban, peri-urban, and rural areas).

- In-migration and out-migration.

- Refugees/internally displaced.

- Religion.

$\circ$ Language.

- Literacy rate.

- Geographic categorization (provinces, territories, districts, etc.). 
- Maternal mortality rate.

- Total fertility rate.

- Infant mortality rate.

Maps

Economics:

- Economic outlook/forecast

- Per capita GNP.

- Income status (low to high levels).

- Poverty rates (at national poverty lines or percentage of population living on US\$2 per day).

- Leading sectors of the economy.

\section{Health and family planning sectors.}

Provide an overview of basic health data and major health issues. This data can be found in publications such as Demographic and Health Survey reports and market status documents (i.e., social marketing sales reports, private-sector assessments published by the World Bank and Abt Associates, and service provision assessment surveys produced by UNFPA). Note that it may be difficult to access some of these documents without contacting the relevant organizations directly to make specific requests, and you may need to pay for the data and/or academic literature. Given the more limited scope of the landscaping phase of TMA, it may be more feasible to search for this data during the following phase, which focuses on market segmentation.

- Key development policy documents as they relate to FP and the role of the private sector and social marketing in particular.

$\circ$ Regulatory bodies:

- Agency name.

- Registration process for new drugs and/or devices.

- Summary of public and private sectors:

- Structure and organization of the health sector which includes donors, multilateral aid agencies, the public, nongovernmental organizations (NGOs), private entities, social marketing agencies, and traditional/informal sectors, and how they interact. This information is presented in graphic form in many health sector review reports.

- To what degree is the public health care system decentralized, and how does this affect FP availability?

- Does the data point to an active and growing private sector for contraceptives (e.g., social marketing and commercial brands)?

- What is the geographic reach of health care workers providing FP products and services? 
What are the functions of each role, and how are they distributed (e.g., what tasks do physicians, nurses, pharmacists, and community-based distributors do, and are they concentrated in urban and peri-urban versus rural areas?)?

- Human resources:

- Types of providers. (How many health care workers are in country by cadre?)

$>$ How many doctors per 1,000 people?

$>$ How many pharmacists per 1,000 people?

$>$ How many community-based agents per 1,000 people?

$>$ How many nurses per 1,000 people?

- Levels of education and training of health care workers.

- Contraceptive administration policies:

- Who is allowed to administer injections and implants? Where?

- Concentration of FP coverage in specific geographic zones.

- Are prescriptions required to dispense oral contraceptives, or are they legally sold over the counter?

\section{Health policy and legal framework for family planning.}

- Do high import taxes act as a barrier to commercial actors' and NGOs' ability to procure contraceptives from outside of the country?

- Are there price controls for contraceptives? If so, what are they?

- Are there legal age restrictions, or consent need from a parent/spouse, that access?

- How long does it typically take for a new product to receive regulatory approval?

- Is there a fast track approval process? If so what are the criteria?

- Are regulatory requirements, required documents and steps in the process articulated and available?

- Do regulations exist for advertising prescription contraceptives or other over-thecounter products?

- What is the country's score on the national Contraceptive Security Index Dashboard? (available at http://deliver.jsi.com/dhome/whatwedo/commsecurity/csmeasuring/csindicators)

- What, if any, are the user fees for contraceptive commodities and services accessed through the public sector?

\section{Reproductive health status.}

(If known, include levels and differentials, such as urban/rural, regional, and service delivery settings based on income level.) 
- Contraceptive prevalence rate (broken down by both modern and traditional methods).

- Unmet need for FP (total, for spacing only, and for limiting only).

- Are FP/maternal and child health and HIV/STI programs integrated within the national health system? Or do they operate as vertical programs?

\section{Family planning.}

$\circ$ What is the current method mix?

- Does public sector FP programming provide access to a full range of methods (pills, injectables, IUDS, etc.)?

- What are the biggest barriers to access in the area in terms of geography, income status, age, etc.?

- Where are different consumer segments from specific wealth quintiles currently getting their FP products and services?

- Organizations and individuals influencing FP policy, programming, and practice:

- Professional associations for pharmacists, physicians, nurses, midwives, etc.

- Faith-based organizations.

- Large commercial/for-profit actors (e.g., contraceptive importers, distributors, hospitals).

- Donor agencies.

- NGOs.

- Which FP products are on the national essential medicines list?

- Structure of service provision and infrastructure:

- Government programs account for __ \% of contraceptive procurement (volume and by method if possible).

- Private sector and/or NGOs account for __ \% of contraceptive procurement (volume and by method if possible).

- Sources of insurance: Central government, regional/local government, employers, NGOs, social insurance or other private insurance.

- Are contraceptives covered by these various insurance plans?

- Out-of-pocket expenditures for FP products and services.

- Donor country strategies Which donors are donating contraceptive commodities? Funding? Restrictions? Are these donors providing support for horizontal or vertical FP programs? Changes in the donor environment will be an important factor when estimating the potential growth of the FP market over the next five years.

- Social marketing information, if available (e.g., geographic focus, which FP methods are being distributed). 
- Supply chain logistics strengths and weaknesses:

- Information on frequency and product type of stockouts, by sector.

- Are there currently any innovative distribution methods for any contraceptives? (This could include any approaches outside of the traditional supply chain, such as community-based distributors, alternative distribution mechanisms, and accredited drugdispensing outlets.)

- Presence of logistics management information systems, high quality of warehouses, push- or pull-type distribution styles, identification of who does procurement, presence of shipping/transport companies.

- Public sector's stated and actual commitment to FP (see Family Planning 2020 Commitment Statement, linked below).

\section{Current health projects involving the private sector.}

- List and provide short descriptions of current FP projects from various organizations that involves the private sector (e.g., corporate social responsibility projects and other interventions geared toward increasing FP access in the workplace). Information on these projects can be found using online search engines or by directly visiting the websites of known organizations.

- List and provide short descriptions of current social marketing projects and any existing TMA country assessments.

\section{Family planning project documents.}

Search websites of local or international organizations working in country to find detailed documents containing TMA-relevant information. Summarize key elements such as the following:

- Initial objectives and planned activities.

- Intended results.

- Extent of achievement of objectives and results.

- Budget and expenditures (by objective if available).

- Length of project.

- Challenges of implementation.

- Specific stakeholders engaged (government, nonprofit, social marketing, and commercial).

\section{Other.}

- Lessons learned from previous experiences identified by your organization or other partners.

- Gaps in knowledge and key questions to be addressed in the screening visits. (Highlight gaps and questions throughout the dossier and summarize them here.)

- A list of contacts for in-country interviews. (Look for organizations, and individual names if possible, that are working on FP and reproductive health in the focus country.) 
10. References for data sources.

- CIA Factbook: https://www.cia.gov/library/publications

- DKT International's contraceptive social marketing statistics: http://www.dktinternational.org/ publications-resources/contraceptive-social-marketing-statistics/

- Family Planning 2020. Commitments: http://www.familyplanning2020.org/commitments

- Health Policy Project. http://www.healthpolicyproject.com/index.cfm?id=publicationsFeatured

- IMS Health data: http://www.imshealth.com/portal/site/imshealth

- Levels and Trends in Child Mortality Report 2014 (UNICEF 2014):

http://www.unicef.org/media/files/Levels and Trends in Child_Mortality 2014.pdf

- MOH website for the country.

- Most recent Demographic and Health Survey data: http://www.dhsprogram.com/

- The Global Fund website, under Grant Portfolio/All Contacts/Country name: http://portfolio.theglobalfund.org/en/Search/Index

- US Agency for International Development Experience Clearinghouse: https://dec.usaid.gov/dec/home/Default.aspx

- PMA 2020. http://www.pma2020.org/

- POPLINE: http://www.popline.org/

- PubMed:http://www.ncbi.nlm.nih.gov/pubmed

- Ross J, Stover J, Adelaja D. Profiles for Family Planning and Reproductive Health Programs in 116 Countries. 2nd ed. Glastonbury, CT: The Futures Group; 2005.

- Reproductive Health Interchange: http://rhi.rhsupplies.org/rhi/index.do

- TMA case studies from UNFPA and Population Services International: http://www.unfpa.org/publications/unfpa-psi-total-market-approach-case-studies

- Track 20 Family Planning Effort Index: http://track20.org/pages/data/FPE

- UNICEF Multiple Indicator Cluster Surveys by country: http://mics.unicef.org/surveys

- UNDP Human Development Indicators: http://hdr.undp.org/en/content/human-development-index-hdi

- Websites of organizations doing family planning work in country (e.g. FHI360; DFID, USAID; SIDA, UNFPA; KFW; Population Reference Bureau; International Planned Parenthood Federation; EngenderHealth; Management Sciences for Health; Population Council; PATH; Pathfinder; Population Services International; and Global Fund to Fight AIDS, Tuberculosis and Malaria).

- World Abortion Policies 2007 (UN 2008): http://www.un.org/esa/population/publications/2007 Abortion Policies Chart/2007AbortionPolicies wallchart.htm 
- World Bank data-by-country page: http://data.worldbank.org/country

- World Bank poverty ratings: http://wdi.worldbank.org/table/2.7

- World Contraceptive Use 2007 (UN 2008):

http://www.un.org/esa/population/publications/contraceptive2007/contraceptive2007.htm

- WHO Global Health Atlas: http://apps.who.int/globalatlas/ WHO Country Cooperation Strategy: http://www.who.int/countryfocus/cooperation strategy/en/

- WHO Mortality Country Fact Sheet: http://www.who.int/mediacentre/factsheets/en/

- WHO Statistical Information System: http://www.who.int/whosis/data/Search.jsp

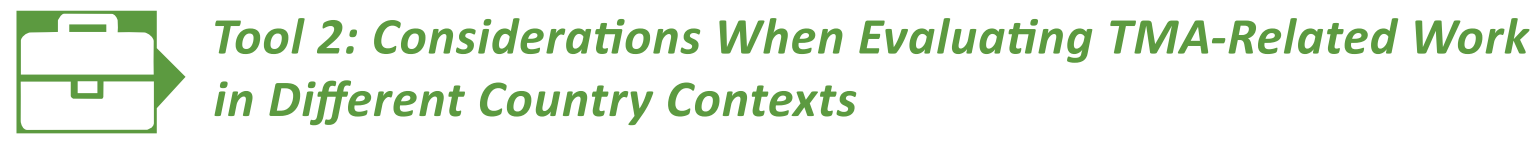

A TMA is an effective strategy for unifying the different contraceptive actors in a country and coordinating their approaches to reach a wide range of population segments, but contraceptive and economic status will vary greatly from nation to nation. Tool 2.1 is a framework that assesses a combination of market and reproductive health factors found in a given country, and Tool 2.2 presents important considerations to use in assessing the market landscape and the country's overall suitability for TMA. Together, these tools allow planners to recommend a specific set of market development strategies that are more likely to lead to a successful TMA implementation.

Tool 2.1. Framework for assessing suitability for a TMA

In 2007, the Reproductive Health Supplies Coalition (RHSC) Market Development Approaches Working Group created a framework for matching market development approaches to specific country environments to better understand the chances of a TMA's success and relevance in a given context. A country typology was outlined to help understand where countries stand in terms of market maturity, using several broad FP market parameters. As part of creating the country typology framework, a matrix was developed to help classify the countries (see Figure A1). 


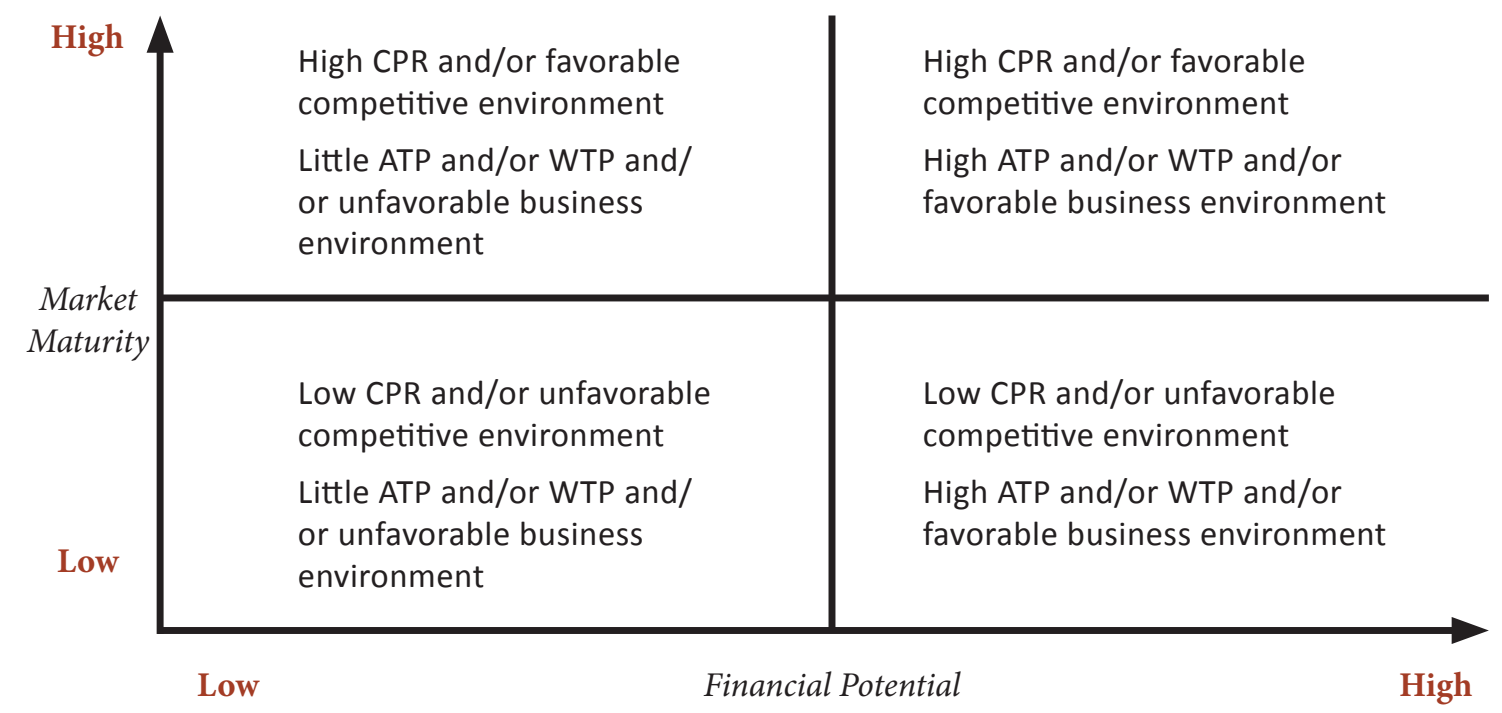

Figure A1. Matrix to help match the market development approach to the country's market environment.

Abbreviations: $\mathrm{ATP}=$ ability to pay; $\mathrm{CPR}=$ contraceptive prevalence rate; $\mathrm{WTP}=$ willingness to pay.

Note: Figure adapted from slide 9 of the RHSC Market Development Approaches Working Group presentation, Country typology: Aiming for MDA success, presented at the RHSC Spring Meeting, April 28, 2006; New York.

Figure A1 separates countries into four broadly distinct groups, based on their respective levels of contraceptive prevalence rate (CPR) and willingness to pay (WTP). Higher rates of CPR and WTP indicate that a nation has a stronger foundation to support TMA activities. Countries with lower rates of one or the other (or both) may require a different set of market development strategies in order to effectively implement a TMA. The matrix above is a tool to be used for conducting a very general assessment of a country's FP environment. It is only a starting point and should not be used to draw definitive conclusions.

\section{Tool 2.2. Considerations for evaluating TMA suitability}

The following questions can be used to guide an analysis of a country's level of readiness for TMA work. Readiness considerations during the landscaping phase are useful to highlight key points on whether a TMA would be appropriate for a country at this time. These questions can help to filter the data gathered during interviews and focus on the important themes that were determined to be the most relevant during a landscape assessment. The questions are also used to inform and frame the qualitative analysis that follows the stakeholder interview process. If the answer to a specific question is yes, then you have identified an area of strength in implementing a TMA. If the answers to a question is no, then you have identified an area that can be targeted for special attention during the TMA planning process. It is important to keep in mind, however, that some answers will not necessarily have strict yes or no responses and that some interpretation will be needed to understand the status of these gray areas during the assessment. 


\section{Questions related to stakeholder perceptions:}

1. Do key stakeholders ${ }^{1}$ understand the concept of TMA and recognize its potential benefits for FP (in all sectors: public, social marketing, private) within their context?

2. Do stakeholders perceive TMA to be a mechanism to further national-level or organizational FP goals?

3. Is the NGO sector willing to work with the government sector to coordinate planning and data sharing to help ensure equitable access to FP products and services?

4. Is the for-profit commercial sector willing to work with the government sector to coordinate planning and data sharing to help ensure equitable access to FP products and services?

5. Do stakeholders perceive that the existing coordination mechanism is capable of developing and implementing a national TMA plan?

6. Are there critical constraints in the current environment that would prevent the implementation of a successful TMA?

\section{Questions related to concrete environmental elements:}

1. Is there an existing coordination mechanism to oversee TMA work in country and that includes all sectors? If not, is there another coordination mechanism that can be strengthened or expanded to reach all of these sectors?

2. Do government FP strategies and policies include references, and are they supportive of TMA principles (e.g., cross-sector collaboration, poverty mapping, product and service delivery focusing strategies, task shifting, demand-side financing/alternative financial schemes, etc.)?

3. Is there specific policy support for and/or experience with public-private partnerships in the health sector generally and the FP sector specifically (e.g., existence of a dedicated public-private partnership unit within the $\mathrm{MOH})$ ?

4. To what extent has the government created a supportive or restrictive operating environment for the private health sector?

5. Does information and/or data exist that will help all stakeholders understand the overall market and design effective TMA interventions (e.g., availability of market segmentation data by contraceptive method)?

6. Are resources (donor and government) available to support increased cross-sector coordination and other potential TMA efforts in the future?

7. Are there opportunities to redirect subsidies, such as shifting how money is allocated and/or shifting distribution/service delivery channels to make programs more cost-effective (e.g., better forms of subsidies to meet the needs of the most marginalized communities and individuals)?

1 Stakeholders may include government actors, nonprofit development partners (e.g., United Nations agencies; bilateral agencies; nongovernmental agencies; social marketing, civil society, and faith-based organizations), and for-profit commercial sector agents (e.g., private practitioners; clinics; hospitals; pharmaceutical importers, wholesalers, distributors, and manufacturers). 


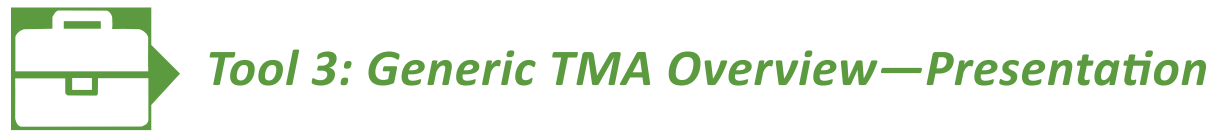

At different points during the TMA landscape assessment it will be necessary to describe TMA and demonstrate its potential to an audience. The following is an example of a generic PowerPoint presentation used to introduce stakeholders to TMA work, proposed activities, and their potential role in a TMA. To make such a presentation most useful, incorporate or insert country-specific information into the generic presentation below.

Slide 1:

Slide 2:

\section{Strengthening Family Planning}

Using the Total Market

Approach (TMA)

TMA Landscape Assessment

\section{Broad overview}

$<$ Insert name of organization/individual $>$ has been tasked to conduct a landscape assessment to determine feasible, country-specific approaches to institutionalize a total market approach.

The project will achieve the following results:

- Analyze family planning stakeholder networks and functional relationships between stakeholders

- Understand family planning policies and systems that would

- Identify opporturies and bariers to instiutionaizing a

government-led TMA

Slide 3:

Country environment

Provides information on the context and country environment in which

andscape assessment will take place. Also provides a high-level overview of important country-specific developments, with a focus on family planning. Examples include:

- Pressure to use donor funds more strategically given fluctuations in externa support

- Insufficient government budgets to provide free FP products and services to

- Increasing demand for FP.

- Evidence that some users who have ability to pay commercial prices are accessing free and subsidized FP products and services. 
Slide 4:

\section{Total Market Approach}

\section{Definition:}

A TMA leverages the comparative advantages of all market sectors to enhance equitable and sustainable family planning across market segments with government coordination and support. It is based on an understanding that meeting the diverse needs of different population segments equitably requires increased attention on coordinating across sectors." Why?

- To increase/sustain contraceptive prevalence and reduce unmet need.

- To enhance financial sustainability of public-sector funding.

- To increase family planning access for the most vulnerable, underserved groups.

Slide 5:

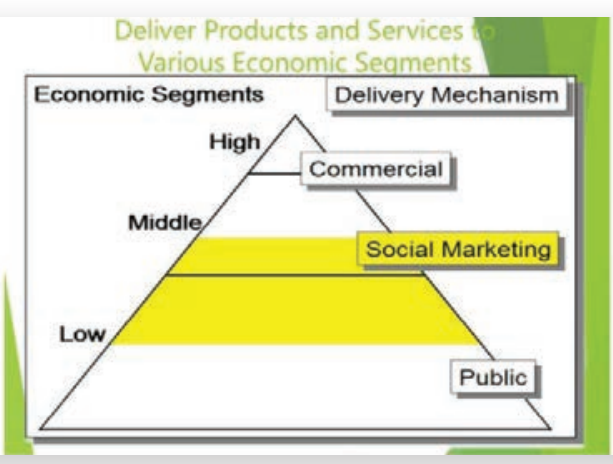

Slide 6:

\section{Key elements of a TMA}

- Coordination of diverse stakeholders

- Identification of market shortcomings through landscaping and research (e.g., market segmentation and forecasting)

- Government uses financial and regulatory resources to assure quality, affordability, and access.

- Efficient use of scarce resources by harnessing the comparative advantage of each sector.

Slide 7:

\section{Government engagement}

- Public-private partnerships for service delivery

- Not just about engaging the private sector

- Not just about product delivery

- Key concepts:

- Partnership

- Government stewardship

- Total market planning

- Lack of engagement between public and private sectors hampers the effectiveness of public health interventions 
Slide 8:

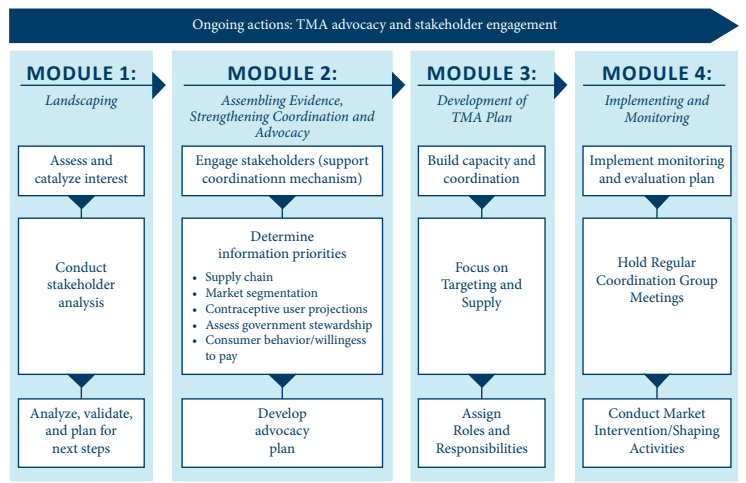

Slide 9:

\section{Relevant contributing factors that lead to a successful TMA}

Background information on government policies, commitments, prior initiatives in the country that are likely to contribute to

future TMA work. For example:

- Government commitment to increasing access to family planning, as articulated in its FP 2020 commitments

- Specific implementing partners experience working with the government in the health arena as well as global expertise supporting TMA

Slide 10:

\section{Proposed TMA activities}

Provide more specifics on what you intend to do, with examples of specific activities and anticipated outcomes. For example:

Conduct in-depth landscape analysis of the current family planning market and work with stakeholders to define a compelling TMA agenda for the future

Expected outcomes:

- Understanding interest and readiness of key in-country stakeholders to implement a

- Identify and prioritize potential constraints in the family planning market that lend themselves
to TMA.

- Recommend strategies to engage public and private sector stakeholders in planning and
coordination roles.

coordination roles.
Identify missing total market data needed to plan future TMA activities.

- Identify mechanisms and means to plan and implement a total market approach in the future.

Slide 11:

\section{Stakeholder engagement}

How will you involve and engage key stakeholders?

Work closely with key stakeholders to understand the environment and identify long-term TMA focus/entry points by:

- Desk review

- Stakeholder interviews

- Meeting to disseminate and validate findings as well as prioritize potential solutions and working modalities 


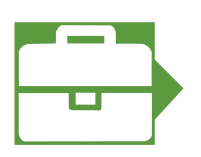

\section{Tool 4: Guidance on the Research Determination Process, Sample Research Protocol on TMA Landscaping, Sample Informed Consent Form, and Sample Generic Stakeholder Interview Guide}

Collecting accurate and useful data about the landscape for a potential TMA begins with the creation of interview documents that can identify all of the information needed. Well-designed interview documents will include questions based on the key TMA readiness considerations listed in Tool 2, which can be used to generate effective qualitative and quantitative data. One of the many uses for this data is that it can then be used to create a variety of informative visual data maps. (The process for making these maps is explained further in Tool 5.)

In addition to being well designed from a data collection standpoint, interview documents must also be written in a way that ensures that those being interviewed are treated with acceptable levels of privacy, dignity, and respect. While every country will have its own set of standards for its institutional review board (IRB), it is imperative that these standards be met while the interview itself is designed and implemented. Although the final approval for a TMA interview must come from a local IRB, some general guidance about the process of designing and implementing research studies is provided below.

Tool 4.1: Checklist and flowchart of considerations for proposed TMA research

This guidance includes some of the language from the PATH Research Determination Committee, but it also includes work from other sources, such as the US Centers for Disease Control and Prevention, the University of Washington, USAID, and the Bill \& Melinda Gates Foundation, among others. The PATH Research Determination Committee also consults with peer organizations in an effort to benchmark our guidance and stay informed of the broader dialogue. Although the information below is focused on United States-based research and ethical processes, it provides useful definitions and clarifications for international settings. 


\section{Does your TMA project have funding from} international donors with specific requirements?

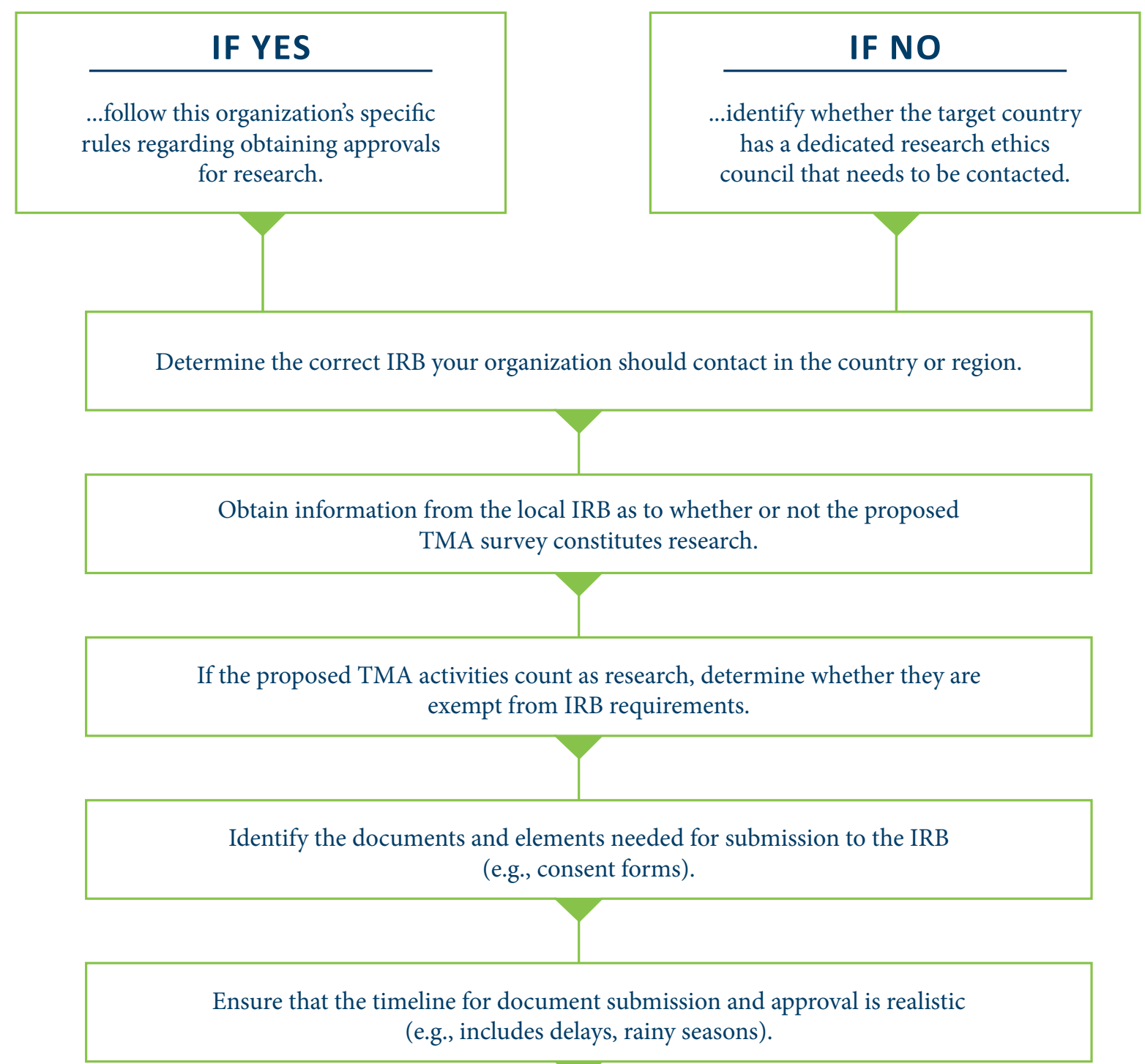




\section{Checklist}

Does the implementing and/or funding institution have specific research ethics requirements?

Many programs and projects funded by international organizations must follow strict procedures to ensure that they are protecting human subjects as well as meeting all of the legal requirements of a given country. If a TMA program has international backing, check with these organizations to find out the proper procedures, documents, and requirements that must be completed to obtain approval to conduct research in country.

\section{Determine whether the focus country has a research ethics committee.}

Because each country has its own sets of rules and procedures governing research ethics, research councils or committees may also exist in certain countries, in which case it will be necessary to seek their approval in addition to that of the REC. There may even be multiple review panels, so it is necessary to fully understand how the ethics review process works in a specific country.

\section{$\square$ Determine the correct REC your organization should contact in the country or region.}

Some countries may have only one established IRB, whereas others may have multiple organizations that exist in different regions, universities, or fields of study. It is important to identify which of these potential IRBs is the right institution to submit the proposed TMA research.

\section{Obtain a determination from the local REC as to whether the proposed TMA survey} constitutes research.

Depending on the intent and scope of the activity and the nature of the data collected and its use, it is possible that the proposed TMA activity may not be considered research and as a result may not require IRB approval. Every country will have its own laws. In the United States, for example, the US Department of Health and Human Services defines research as "systematic investigation, including research development, testing and evaluation, designed to develop or contribute to generalizable knowledge." In addition, information collected for the purposes of presenting or publishing is likely to be considered research. If the proposed TMA work meets one of these definitions, it will probably be necessary to prepare documents to submit to the local REC to gain approval to conduct the survey. Again, specific country rules will apply, but in the United States the general rule is that a project that involves (a) identifiable private information or (b) interactions or interventions with individuals, such as focus groups or surveys, is considered research and must obtain IRB approval.

If you are unsure about what constitutes research, always err on the side of caution and contact the REC before beginning work.

- Survey/interview participants are not from vulnerable or special populations (e.g., pregnant women, cognitively impaired individuals, minors).

Again, if it is possible that the proposed TMA activity could be exempted from IRB approval, be sure to confirm this with the REC before beginning work. 


\section{Identify all documents required for IRB submission.}

Most IRBs require similar documentation, such as the research protocol, questionnaire, consent forms, and confidentiality protections etc. and budget narratives. All relevant documents must be submitted as a package for review. It is critical that all required documents are prepared and presented in the way required by the IRB. The IRB approval of the work is based on these documents, any deviation from protocol, for example is a breach of that approval and can jeopardize the research. Ensure the timeline for document submission and approval is realistic.

Sometimes even well-planned programs and projects can face unexpected delays. Government or academic delays, senior leaders being unavailable, and holiday leave can all delay IRB approval of TMA research., When preparing for IRB approval, consider the possibility of such disruptions. Leave enough time between the date the documentation is submitted for IRB approval and the beginning of the planned TMA research to adjust these plans if necessary.

\section{Tool 4.2: Sample TMA stakeholder interview protocol}

The sample interview protocol, which was adapted from PATH's stakeholder analysis in Uganda that required IRB approval, provides an overview of how to approach TMA interviews. Note that country-specific content will need to be included, and that the information in this overview may not be appropriate for all country contexts. Particular areas that will likely need to be changed are noted with brackets: [context-specific text]. Tool 4.2 can be used both for research determination and for IRB submission, as both require a research protocol as part of the application process.

\section{Rationale}

Building on a desk review, which identifies key factors for assessing the suitability of a proposed TMA, [context-specific text] will undertake a stakeholder analysis by interviewing FP stakeholders (e.g., donors, government, NGOs, commercial distributors, technical assistance and research agencies, civil society groups, and professional associations) to determine the in-country FP network.

\section{Primary Objectives}

This landscaping exercise is aimed at assessing the potential for implementing a TMA in [context-specific text]. The desired outcome is to enhance equitable and sustained access to FP in [context-specific text] by collecting the views of key stakeholders and thus allowing FP programmers to identify opportunities and make more efficient use of FP resources by mobilizing different market segments.

\section{Participants}

\section{Participant selection}

[Context-specific text] expects to interview key informants who represent the major organizations involved in the FP market. This includes government, donors, social marketing organizations, and commercial as well as 
nonprofit service providers. We have identified these organizations as key stakeholders based on earlier research, as well as through recommendations from other actors involved in reproductive health and FP.

Number of participants involved

[Context-specific text] expects to interview a maximum of 30 stakeholders drawn from every major organization that represents the total market approach (TMA), such as government, donors, social marketing organizations, and nonprofit and commercial providers of products and/or services. Depending on availability, we will engage with collaborating organizations to participate in this data collection process.

\section{Location}

The interviews will take place primarily in major urban areas where stakeholders can be accessed, such as the capital cities of [context-specific text]. Additional interviews will be conducted in [context-specific text], where key stakeholders were identified during the stakeholder analysis and desk review research. It is important to note that sampling is opportunistic and is based on the roles and influence of respondents around the family planning market.

\section{Methodology}

[Context-specific text] will conduct the stakeholder interviews according to the guidelines as follows. A sample informed consent form is included as Tool 4.3, and a sample interview guide is included as Tool 4.4.

\section{General information}

The following guide is intended to orient the interviewer and ensure that key questions are answered. It is an outline, but not a script. In most cases there will be a list of open-ended questions relevant to understanding the suitability of the TMA environment in the target country. At the end of the interview, the interviewer can ask for general recommendations. The interviewer should take the liberty of asking probing questions during the interview to help clarify the informant's comments and obtain more detailed information.

There are three main components to the interview:

\section{Introduction:}

Be sure to confirm the time available and make sure the setting is private enough that interviewees feel comfortable with the surroundings. Then introduce the facilitator and provide general information on the purpose of the interview.

In some countries TMA work may have been carried out previously. In these cases specific details should have been uncovered during the desk review. You can then ask several general questions regarding this work to orient the interviewee as to what constitutes a TMA.

- Stated objective.

- Approximate dates of TMA activity.

- Key activities [specify the health area and the products based on desk review research). 
- Collaborating partners (e.g., social marketing organizations, public and private service delivery organizations, technical agencies working in FP, and other key stakeholders, especially public-sector stakeholders).

In these cases the interviewer should avoid providing too much background information on previous TMA work or their impressions the prior work. The interview is intended to gauge the stakeholder's familiarity with what took place, so mentioning specific objectives and activities may unduly influence the respondent's answers.

Next, explain why the interviewee's cooperation is important by providing an idea of how the information will be used.

Also assure interviewees that the information will be collected in a confidential manner (see the consent form in Tool 4.3). Tell interviewees that anything they wish to keep "off the record" will not be included in the report, and that there is no obligation to reference the source of sensitive information.

Sample language at the start of each interview:

"[Context-specific text] is conducting research with key informants including government officials, family planning providers, international donors and multilateral organizations, NGOs, and suppliers. The goal is to improve understanding of the roles and involvement of stakeholders in family planning in [context-specific text] and assess their perceptions toward past, current, and future TMA programming. The goal of the project is to enhance future total market approaches by determining metrics and best practices from previous and existing initiatives.

This interview will be an opportunity to discuss constraints, new developments and changes attributable to the intervention(s), and future TMA plans. You are invited to participate in this interview because of your involvement and expertise in [context-specific text].

The findings from these interviews will be synthesized and analyzed to develop a presentation containing the draft topline findings. This presentation will be shared with you, and a subsequent teleconference will be organized to obtain feedback on the content. You are welcome to provide feedback by email as well, if that is possible. We are also prepared to disseminate the findings more widely, nationally and globally, to strengthen future TMA interventions."

\section{Interview:}

Proceed with the interview based on the interview guide provided in Tool 4.4.

\section{Closing questions and summary:}

The closing questions provide an opportunity for the key informant to give any additional information or comments. If time permits, feel free to ask for recommendations or solutions to address problems discussed beforehand. This could be the very last question.

Also, if time permits, quickly summarize the major comments heard throughout the interview and ask if you have covered all the major points from the informant's perspective. Ask if there is anything else they would like to tell you and if there are other people they would recommend be interviewed. 
Sample language for the end of each interview:

"Thank you very much for your participation. We are conducting interviews with approximately [context-specific text] in the country. After we compile the comments, we plan to hold a dissemination workshop with all of the stakeholders to present and validate the topline findings and discuss key recommendations."

After the stakeholder interviews [context-specific text] will analyze the interview data using [context-specific text] (or equivalent qualitative analysis software). [Context-specific text] will compare and contrast information from each interview transcript to identify themes that resonate across individuals or types of respondents (e.g., donors or government or NGO staff), or that were distinct to a particular individual. Information coding will follow an inductive approach, with codes and themes evolving organically from meeting notes. Analysis will look at respondents' convergence (or divergence) of views on the success of the initiative in terms of achieving intended results, implementation processes, unexpected constraints, new developments, and recommendations for future TMA work. Finally, research needs and evidence gaps will be identified and documented.

To validate findings prior to dissemination, [context-specific text] will share the draft findings with relevant collaborating organizations and key government stakeholders in [context-specific text]. [Context-specific text] staff will follow up as necessary to validate findings, and a workshop will be held with these individuals to obtain feedback on the content and presentation of the results; feedback by email will also be solicited. This will provide an opportunity to review the results, sharpen the interpretation of the data, clarify any areas of concern, and target dissemination and use of the findings.

\section{Tool 4.3: Sample informed consent form}

\section{Study title: [context-specific text]}

Thank you for agreeing to take part in a key informant interview that examines the possibility of implementing a total market approach (TMA) in [context-specific text].

Before you decide whether to participate, you need to understand why the research is being done and what it will involve. Please take the time to read or listen as I read the following information. You may talk to others about the study if you wish. Please ask me if there is anything that is not clear, or if you would like more information. When all of your questions have been answered and you feel that you understand this study, you will be asked if you wish to participate in the study, and if yes, you will be asked to sign this informed consent form. You will be given a signed copy to keep.

\section{Purpose of the study and study requirements}

What is the study? The purpose of the study is to understand the landscape in [context-specific text] in preparation for initiating a total market approach (TMA). Specifically, the study will:

- Analyze family planning stakeholder networks across sectors and functional relationships between stakeholders. 
- Identify specific family planning issues and priorities in [context-specific text] that would lend themselves to total market solutions.

- Understand family planning policies and systems that would be involved in implementation of a TMA.

- Weigh opportunities and barriers to institutionalizing a government-led TMA.

- Identify research needs and evidence gaps.

- Recommend first steps to implementing a comprehensive total market approach, if the environment is deemed suitable for further work in this area.

We will collect data in two ways. First, we have already conducted a desk review of documentation on TMA experience and collected secondary data on the market status in each country. Second, we will conduct approximately $30 \mathrm{key}$ informant interviews with stakeholders who represent the major organizations likely to be involved in the TMA.

This research has been funded by [context-specific text]. [Context-specific text] is a project partner and is carrying out this study on TMAs.

Why have I been invited to take part? You have been identified as a key stakeholder in your country's TMA, which means that you were substantively involved in TMA-related activities such as policymaking, implementation, advocacy, social marketing, or other activities.

What will happen if I take part? If you agree to take part in the study, we will ask you to sign this form. You will also be asked to participate in an individual interview asking you about your experiences with the implementation of the TMA in your country. Participation in this interview is voluntary.

How long will the interview last? The interview will take approximately [context-specific text].

We may contact you again to clarify your responses to the interview questions or to seek limited additional information. We will also share the results of the research with you prior to disseminating them and you will have an opportunity to provide feedback on the presentation of results.

\section{Risks}

What are the risks of the study? An inconvenience may be the time and effort you take to be a participant. You do not have to respond to any question that makes you uncomfortable. You may end the interview at any time.

A risk may be a breach of confidentiality (in which something you say is accidentally provided to others), but we will take precautions to see that this does not happen.

\section{Benefits}

What are the benefits of participating? There are no direct benefits to you for participating in the study. You may find an indirect benefit in knowing you have participated in an important study that could help improve future efforts to increase access to family planning services through TMAs. 


\section{Confidentiality}

Will my participation in the study be kept confidential? The information that is collected during this interview will be kept private. Your participation in the study will we acknowledged but no quotes will be attributed to you.

The study team will make every effort to protect your privacy and maintain the confidentiality of all the information that you provide. Your name or other identifiers will not be included in reports from this study. Data will be stored in a project computer dedicated to this study that only the study team can access. Steps will be taken to ensure that the interview transcripts/notes will not be accessible to others, and identifiers other than names will be used so that information cannot be linked to specific individuals. While we may incorporate what you say in our research, we will not record or use your name in any way. We will specifically request your permission to include any quote attributed to you during the interview before we include it in any report.

\section{Voluntariness}

What are my rights as a research participant/subject? Your participation in this study is completely voluntary. Participation in this study will not have any impact on your current employment situation, and your employer will not be told that you were asked to participate in this study.

If you agree to participate in this study, you may end your participation at any time. If you decide to take part, you are free to skip any questions. You are free to withdraw at any time without affecting your relationship with [context-specific text].

\section{Additional information}

What will I receive for participating? No compensation will be provided.

What will happen to the results of the research study? The results of the study will be analyzed using a qualitative data analysis software program to identify themes from the interviews. Following the analysis of the interview data, [context-specific text] will email the draft findings to interviewees, relevant collaborating organizations, and key government stakeholders. These individuals will be contacted individually by researchers from the study and invited to give feedback on the content and presentation of the results; additional feedback by email will be solicited. A one-day dissemination workshop will be held with the key stakeholders.

The findings from these interviews will be reviewed, published, and disseminated globally through meeting presentations, posting on relevant websites, and by sharing the findings with project partners and key stakeholders in a half-day meeting in Washington, DC.

Who has reviewed the study for ethical issues? This study has been reviewed by [context-specific text] in [context-specific text].

What if I need more information? If you have a concern about any aspect of the study, you should ask to speak to the researchers, who will do their best to answer your questions. You may call [context-specific text].

What if there is a problem? Any complaint about the way you have been treated during the study or any possible harm you might suffer will be addressed. Please contact [context-specific text]. 


\section{Subject statement}

I have read the informed consent for this study. I have received an explanation of the planned research, procedures, risks, benefits, and privacy of my personal information. I agree to take part in this study. I understand that my participation in this study is voluntary.

Your name

Your signature:

Date:

Investigator or person who conducted informed consent discussion: I confirm that I have personally explained the nature and extent of the planned research, study procedures, potential risks and benefits, and confidentiality of personal information.

Name of person obtaining consent:

Signature of person obtaining consent: Date:

\section{Tool 4.4: Generic interview guide}

In determining the best approach to data collection, consider a combination of both quantitative and qualitative questions. Quantitative responses provide an opportunity to confirm specific information gleaned during the desk review, whereas qualitative responses can add nuance and richness to the analysis. This interview guide will help steer the collection of relevant TMA-related data needed for the landscape assessment. Because of the length of the questionnaire, it will likely be necessary to draw selectively from the questions below to meet the specific interviewee's needs.

It is recommended that TMA planners select a trained interviewer who is comfortable enough with the total market landscape to ask clarifying and probing questions as needed, as well as to contribute to or lead the analysis of findings. Take the time needed to pretest the interview guide for timing as well as for redundancy and clarity of questions. In addition, depending on the country, these data collection instruments may need to be translated and then tested in translation.

\section{Interview guide}

[Begin by introducing yourself and your work. Ask the participant for name, position, and relation to the field of FP. It is important to allow the interviewee to feel comfortable to ensure that you receive honest and accurate information during the interview.

Note: this sample is designed for interviewing government actors specifically, but it can easily be modified for surveying individuals from other sectors, such as donors/multilaterals, NGOs, commercial-sector, and nonprofit FP providers.] 


\section{General family planning landscape}

1. I am going to ask you some questions about your perceptions of FP programs. Here is a list of things that may be challenges in the provision of family planning services in [country name]. As I read each one, please tell me if you think it is a major challenge, a moderate challenge, a minor challenge, or not a challenge.

\begin{tabular}{|c|c|c|c|c|c|c|c|}
\hline & & $\begin{array}{c}\text { NOT A } \\
\text { CHALLENGE }\end{array}$ & MINOR & MODERATE & MAJOR & $\begin{array}{l}\text { DON'T } \\
\text { KNOW }\end{array}$ & N/A \\
\hline $1 a$ & $\begin{array}{l}\text { Quality of public-sector } \\
\text { services. }\end{array}$ & $\square$ & $\square$ & $\square$ & $\square$ & $\square$ & $\square$ \\
\hline $1 b$ & $\begin{array}{l}\text { Quality of nonprofit private- } \\
\text { sector services. }\end{array}$ & $\square$ & $\square$ & $\square$ & $\square$ & $\square$ & $\square$ \\
\hline $1 c$ & $\begin{array}{l}\text { Quality of for-profit } \\
\text { commercial-sector services. }\end{array}$ & $\square$ & $\square$ & $\square$ & $\square$ & $\square$ & $\square$ \\
\hline $1 d$ & $\begin{array}{l}\text { Availability of public-sector } \\
\text { services. }\end{array}$ & $\square$ & $\square$ & $\square$ & $\square$ & $\square$ & $\square$ \\
\hline $1 e$ & $\begin{array}{l}\text { Availability of nonprofit } \\
\text { private-sector services. }\end{array}$ & $\square$ & $\square$ & $\square$ & $\square$ & $\square$ & $\square$ \\
\hline $1 \mathrm{f}$ & $\begin{array}{l}\text { Availability of for-profit } \\
\text { commercial-sector services. }\end{array}$ & $\square$ & $\square$ & $\square$ & $\square$ & $\square$ & $\square$ \\
\hline $1 g$ & $\begin{array}{l}\text { Government financing of } \\
\text { public-sector health services. }\end{array}$ & $\square$ & $\square$ & $\square$ & $\square$ & $\square$ & $\square$ \\
\hline $1 \mathrm{~h}$ & $\begin{array}{l}\text { Access to family planning } \\
\text { services for underserved } \\
\text { populations. }\end{array}$ & $\square$ & $\square$ & $\square$ & $\square$ & $\square$ & $\square$ \\
\hline $1 \mathrm{i}$ & $\begin{array}{l}\text { Affordability of family } \\
\text { planning services to } \\
\text { underserved populations. }\end{array}$ & $\square$ & $\square$ & $\square$ & $\square$ & $\square$ & $\square$ \\
\hline $1 \mathrm{j}$ & $\begin{array}{l}\text { Sustainability of current } \\
\text { level of public-sector service } \\
\text { provision. }\end{array}$ & $\square$ & $\square$ & $\square$ & $\square$ & $\square$ & $\square$ \\
\hline
\end{tabular}

2. Please give specific examples of how the public sector attempts to increase equity by reaching the most underserved population segments through its family planning program. [Note: it may be useful to clarify how the interviewee defines equity and underserved populations. If necessary, provide examples based on findings from the desk review.] 
3. Does the government have strategies, plans, and protocols in place to focus family planning products and services to reach a particular population group or groups? [For example, adolescents or other underserved populations.]

If so, please describe.

4. In your opinion, to what extent are these government strategies, plans, or protocols working effectively? Why or why not?

5. What role do you see for the private sector in providing health services and products, particularly for underserved population groups?

\begin{tabular}{|c|c|}
\hline $\begin{array}{l}\text { PRIVATE-SECTOR } \\
\text { CATEGORIES }\end{array}$ & ROLE IN REACHING UNDERSERVED POPULATIONS \\
\hline Nonprofit & \\
\hline For profit/commercial & \\
\hline
\end{tabular}

\section{General market awareness and perspectives}

6. Are you familiar with the term total market approach? If so, how would you define it? [Note: Be prepared to add to or supplement the interviewee's definition and give examples of activities that are generally considered TMA, expanding upon what was described during the introduction.]

7. Can you provide examples of TMA activities that have taken place previously in [Country Name]?

8. Are you aware of specific total market approach activities going on now-managed either by the government or by another group? Please explain. [Note: this follow-up question may not be necessary if the answer to question 6 encompasses current TMA work.]

9. Are there any policies or legislation enacted that are supportive of the total market approach? [Note: refer to specific policies (e.g., the National Costed Implementation Plan for FP) or to legislation gleaned from the desk review.]

10. Do you think the concept of a total market approach could be useful in [Country Name]?

$\circ$ Why or why not? 
11. As I read each of the next items, tell me how you think it would contribute to efforts to strengthen FP services and produce equitable access and sustainability of the market in [Country Name]. Would it have high, moderate, or low impact?

\begin{tabular}{|c|c|c|c|c|}
\hline & & HIGH & MODERATE & LOW \\
\hline $11 a$ & $\begin{array}{l}\text { Additional information/data on FP market } \\
\text { segmented by demographics, geography, wealth } \\
\text { quintile, etc. }\end{array}$ & & & \\
\hline $11 b$ & Supportive national policies. & & & \\
\hline $11 c$ & $\begin{array}{l}\text { Increased monitoring and regular reviews of key } \\
\text { market data. }\end{array}$ & & & \\
\hline $11 d$ & $\begin{array}{l}\text { Better communication between different sectors/ } \\
\text { active coordinating group/mechanism. [Probe: } \\
\text { Is communication with certain sectors better } \\
\text { than others?] }\end{array}$ & & & \\
\hline $11 \mathrm{e}$ & $\begin{array}{l}\text { Improvements in national and district supply chain } \\
\text { logistics systems. }\end{array}$ & & & \\
\hline $11 f$ & $\begin{array}{l}\text { Better focusing of the distribution of free public- } \\
\text { sector and subsidized products and services. }\end{array}$ & & & \\
\hline $11 \mathrm{~g}$ & $\begin{array}{l}\text { National policies approving health provider } \\
\text { task shifting. }\end{array}$ & & & \\
\hline
\end{tabular}

12. Is there another factor that you think would contribute in an important way to a successful TMA effort? Please explain.

13. To what extent do you think a total market approach would contribute to your government's national or international commitments to improve equitable and sustainable access to family planning? Please explain.

14. Are there factors that may act as constraints to TMA programming in [Country Name]? [Note: ask the interviewee to cite examples].

15. If a TMA were to be initiated in [Country Name], at what level would it have the most impact-national or subnational? Why? [Note: probe to find out if FP activities are generally rolled out initially from the highest possible national decision-maker level and then taken on by the lowest subnational level, or whether decentralized levels exercise significant autonomy.] 
16. The capacity of the public sector to steward coordination of public and private sectors is an important attribute of a successful TMA. Do you think the central government's capacity in this area would be strong, moderate, or weak?

Please explain. [Note: probe for specific government competencies that might be outstanding or lacking.]

\begin{tabular}{|c|c|c|}
\hline STRONG & MODERATE & WEAK \\
\hline$\square$ & $\square$ & $\square$ \\
\hline
\end{tabular}

\section{Collaboration and coordination}

17. Please name the top three or four stakeholders who would have the most influence on programs using TMA principles in [Country Name]. Stakeholders can come from any sector-public, private, or nongovernmental. How might these people affect the success of any future work in this area? [Note: as appropriate, probe to determine the degree to which these people influence national policy and have decision-making authority. Note that their influence can be either negative or positive.]

\begin{tabular}{|c|c|c|}
\hline $\begin{array}{c}\text { NAME OF STAKEHOLDER, } \\
\text { AGENCY, OR DEPARTMENT }\end{array}$ & $\begin{array}{c}\text { HOW THIS PERSON } \\
\text { IS LIKELY TO INFLUENCE } \\
\text { TMA PROGRAMMING }\end{array}$ \\
\hline & & \\
\hline & & \\
\hline
\end{tabular}

18. In undertaking any new initiative, it is helpful to consider existing structures through which it can work. Is there a formal standing/permanent coordination mechanism to engage with the different sectors involved in providing family planning services and commodities?

a. If yes, mention different bodies identified from the desk review and ask the following:

- What is the purpose of the group?

- What is it called?

- What types of organizations routinely participate?

- Does the for-profit sector participate in this group? How is it represented?

- Who convenes the group and sets the agenda?

- When was the last meeting?

- What specific activities has this group undertaken, and what has been their success?

b. If no, ask whether it is feasible that one could be established and what the opportunities and barriers are to doing so? 
19. To what degree do you believe this coordination mechanism could be successful in developing and implementing an action plan?

Likely to be able to develop and implement a plan. [Why/Why not?]

Likely to be able to develop a plan, but unlikely to implement it. [Why/Why not?]

U Unlikely to be able to develop a plan. [Why/Why not?]

$\square \quad$ Uncertain.

[Note: if the current mechanisms are said not to be working as expected, or not entirely suitable, ask the interviewee to envision the most effective mechanism.]

20. [Optional] Please recommend what you think would be the most effective mechanism for bringing the public, nonprofit/NGO, and commercial sectors together to consider TMA perspectives and work on the development of a total market approach.

21. In addition to the $\mathrm{MOH}$, what other government agencies are involved now, or should be involved, in order for TMA activities in [Country Name] to make progress in this area?

\begin{tabular}{|l|c|c|}
\hline NAME OF GOVERNMENT AGENCY & $\begin{array}{c}\text { CURRENTLY } \\
\text { INVOLVED }\end{array}$ & $\begin{array}{c}\text { SHOULD BE } \\
\text { INVOLVED }\end{array}$ \\
\hline & $\square$ & $\square$ \\
\hline & $\square$ & $\square$ \\
\hline
\end{tabular}




\section{Collaboration with nonprofit/NGO and for-profit/private sectors}

22. In general, how would you describe the current level of coordination between your department and its family planning partners from the nonprofit/NGO and for-profit/private sectors, as relates to the delivery of contraceptive products and services?

\begin{tabular}{|c|c|c|c|c|}
\hline & \multicolumn{4}{|c|}{ COORDINATION } \\
\hline & STRONG & $\begin{array}{l}\text { OCCURS, BUT } \\
\text { INCONSISTENT }\end{array}$ & INFREQUENT & NONEXISTENT \\
\hline NGOs implementing social ma & & & & \\
\hline Faith-based organizations & & & & \\
\hline Civil society organizations & & & & \\
\hline $\begin{array}{l}\text { For-profit private/commercial } \\
\text { entities }\end{array}$ & & & & \\
\hline Other & & & & \\
\hline
\end{tabular}

23. Is there a functioning exchange of procurement data about contraceptive products between the public and nonprofit/NGO and for-profit/private sectors?

\begin{tabular}{|l|c|c|c|}
\hline & $\begin{array}{c}\text { PROCUREMENT } \\
\text { DATA PROVIDED } \\
\text { REGULARLY }\end{array}$ & $\begin{array}{c}\text { PROCUREMENT DATA } \\
\text { PROVIDED IRREGULARLY }\end{array}$ & $\begin{array}{c}\text { PROCUREMENT } \\
\text { (E.G., ONCE A YEAR) }\end{array}$ \\
\hline SHARED \\
\hline Nonprofit/NGO sector & & & \\
\hline Social marketing & & & \\
\hline For-profit/private/ commercial & & & \\
sector & & & \\
\hline
\end{tabular}

- How is the information shared?

- How is it used and by whom? [Probe: such as during the annual quantification exercise?] 
24. Is there a functioning exchange of distribution data about contraceptive products and service delivery between the public and nonprofit/NGO and for-profit/private sectors?

\begin{tabular}{|l|l|l|l|}
\hline & $\begin{array}{c}\text { PROCUREMENT } \\
\text { DATA PROVIDED } \\
\text { REGULARLY }\end{array}$ & $\begin{array}{c}\text { PROCUREMENT DATA } \\
\text { PROVIDED IRREGULARLY } \\
\text { (E.G., ONCE A YEAR) }\end{array}$ & $\begin{array}{c}\text { PROCUREMENT } \\
\text { DATA NOT } \\
\text { SHARED }\end{array}$ \\
\hline Nonprofit/NGO sector & & & \\
\hline Social marketing & & & \\
\hline $\begin{array}{l}\text { For-profit/private/ commercial } \\
\text { sector }\end{array}$ & & & \\
\hline
\end{tabular}

- How is the information shared?

- How is it used? [Probe: Such as during the annual quantification exercise?]

25. To what extent do you think that public-private collaboration contributes to equitable and sustainable access to family planning services?

\begin{tabular}{|c|c|c|c|}
\hline \multicolumn{2}{|c|}{ EQUITABLE } & \multicolumn{2}{|c|}{ SUSTAINABLE } \\
\hline & Critical & $\square$ & Critical \\
\hline & Important & $\square$ & Important \\
\hline & Limited & $\square$ & Limited \\
\hline & Disagree & $\square$ & Disagree \\
\hline
\end{tabular}

$\circ$ Why?

26. Do any for-profit/commercial-sector players stand out particularly in terms of coordination and collaboration?

$\circ$ Why? 
27. For each of the following, please note the situation in your country regarding ways that the government may currently be engaging the private sector in family planning:

\begin{tabular}{|c|c|c|c|c|}
\hline & & YES & NO & $\begin{array}{l}\text { DON'T } \\
\text { KNOW }\end{array}$ \\
\hline $27 a$ & $\begin{array}{l}\text { The government includes distribution data from } \\
\text { the private nonprofit/NGO sector in its family } \\
\text { planning statistics. }\end{array}$ & & & \\
\hline $27 b$ & $\begin{array}{l}\text { The government includes distribution data from the } \\
\text { for-profit/commercial sector in its FP statistics. }\end{array}$ & & & \\
\hline $27 c$ & $\begin{array}{l}\text { Product and service data from the commercial sector } \\
\text { is used by the } \mathrm{MOH} \text { when planning and forecasting } \\
\text { commodities for procurement. }\end{array}$ & & & \\
\hline $27 d$ & $\begin{array}{l}\text { Government trainings are open to private-sector } \\
\text { health providers. }\end{array}$ & & & \\
\hline $27 e$ & $\begin{array}{l}\text { The government contracts with the private sector to } \\
\text { provide services. }\end{array}$ & & & \\
\hline $27 f$ & $\begin{array}{l}\text { There are situations when the government provides the } \\
\text { private sector with family planning products. }\end{array}$ & & & \\
\hline $27 \mathrm{~g}$ & $\begin{array}{l}\text { Public-private partnerships exist in which the } \\
\text { government has formalized linkages with corporate } \\
\text { social responsibility programs. }\end{array}$ & & & \\
\hline
\end{tabular}

28. Please indicate whether there is a consultative process to engage the private health sector in regulations that affect their operating environment in the following areas, as relates to family planning.

Tariffs and taxes.

Medicines, medical devices, and clinical services pricing.

Medicines, medical devices, and clinical services regulatory policies.

- Facility licensing and regulation.

- Provision of registration/licensing.

Other (please elaborate). 
29. Are there specific government policies that encourage or support increased engagement with the commercial health sector? If yes, what is the name of the policy, and how effective do you think this policy has been?

\section{Availability of FP market data}

30. Do you know of relevant assessments or market studies, produced in the last three years, that cover one or more of the three sectors (public, NGO/social marketing and commercial) and that we can reference to extract total market approach family planning data? Please specify. [Note: as appropriate, mention some of the studies already identified during desk review, and ask if the interviewee can recommend others worth reviewing.]

31. What additional information on the family planning market do you think is needed to improve coordination and efficient allocation of resources in [Country Name]?

\begin{tabular}{|l|l|}
\hline \multicolumn{1}{|c|}{ EXAMPLES OF GENERAL MARKET RESEARCH CATEGORIES } \\
\hline $\begin{array}{l}\text { Sources of supplies. } \\
\text { Total market size/volume (by contraceptive product and distribution channel, for } \\
\text { both traditional and nontraditional outlets). } \\
\text { Market composition (key actors and brands). } \\
\text { Market subsidies. }\end{array}$ \\
$\begin{array}{l}\text { Universe of need and projecting uptake. } \\
\text { Consumer segmentation and profiles (broken out by key and general population). } \\
\text { Equity index. }\end{array}$ \\
\hline
\end{tabular}

[Note: as appropriate, cite examples of data gaps identified during the desk review.]

\section{Projecting impact and potential outcomes from a TMA}

32. What, in your opinion, would be the most useful benefits or outcomes resulting from a concerted TMA in [Country Name]? [Note: if the interviewee has no experience with TMA, this will be difficult to answer.]

33. Are there any other factors you think should be considered that could contribute in a significant way to more equitable access and sustainability of the family planning market? Please explain.

34. Can you envision any negative or unintended consequences or ripple effects resulting from total market approach activities? Please explain. [Note: if necessary, list possible answers. For example, interventions that engage current suppliers in long-term contracts (e.g., volume guarantees) and inadvertently discourage new suppliers from entering the market]. 


\section{Closing questions and summary}

This is an opportunity to wrap up the interview and allow the key informant an opportunity to provide any additional information or comments.

35. Please list any additional priorities you think are important to ensure access, equity, and sustainability of family planning. [Note: list some possibilities, such as improving annual quantification exercises or improving logistics to minimize stockouts.]

36. What is the most important piece of advice or recommendation you could offer about total market approach programming for future family planning initiatives?

37. Is your department/institution interested in participating more actively in promoting TMA to increase the equitable and sustained delivery of FP products and services?

- If yes, what would be your priorities or next steps to promote TMA activities going forward? 


\section{Tool 5: Network Mapping}

One effective way of better understanding the TMA landscape is to create visual maps of the various actors capturing the influencing factors that make up a country or regional environment. Although there is no single approach to creating a stakeholder or network map, the graphic display of, for example, organizational relationships can bring new understanding to critical participants in the market environment. Mapping can suggest not only where key actors fall on a continuum related to TMA, but in which direction they might be persuaded to shift through advocacy. Maps can also highlight real possibilities of cooperation and connection or identify where a change agent needs to devote time and effort to build new relations or change positions.

Once the key actors and organizations have been identified, mapping can be used as as the next step is to find out more about the pressures they face in their various roles. Forces and pressures placed upon the actors are revealed in the demands they must respond to on a daily basis. Understanding these motivations using mapping will provide insights into how they are likely to respond to TMA programming.

Table A1 presents four ways to present your findings by using maps.

\begin{tabular}{|l|l|l|}
\hline \multicolumn{1}{|c|}{ TYPE OF MAP } & \multicolumn{1}{|c|}{ REASON TO USE IT } & AVAILABILITY \\
\hline Word cloud & $\begin{array}{l}\text { To identify the most common themes, } \\
\text { ideas, and actors. }\end{array}$ & Free, available online. \\
\hline Policy map & $\begin{array}{l}\text { To help identify policies, actors, and } \\
\text { relationships that may support or } \\
\text { hinder your operation. }\end{array}$ & $\begin{array}{l}\text { Free program called PolicyMaker, available } \\
\text { online at } \\
\text { www.polimap.com/download.html. }\end{array}$ \\
\hline Radar map & $\begin{array}{l}\text { To identify links and associations } \\
\text { between stakeholders. }\end{array}$ & Requires Microsoft Excel. \\
\hline $\begin{array}{l}\text { Network map } \\
\text { (Advanced) }\end{array}$ & $\begin{array}{l}\text { To obtain a more realistic depiction of } \\
\text { connections and interactions between } \\
\text { various stakeholders. }\end{array}$ & $\begin{array}{l}\text { Special software required; some is } \\
\text { available online for free, and some requires } \\
\text { payment. }\end{array}$ \\
\hline
\end{tabular}

Table A1. Four types of maps.

The examples that follow, in Tools 5.1, 5.2, 5.3, and 5.4, demonstrate the various mapping strategies that may be implemented when assessing the roles of key actors and organizations involved in a TMA.

Steps for designing a map may include the following:

- Determine who belongs in your map.

- Assess organizational and stakeholder connections.

- Determine the nature of relationships between organizations or key actors. 


\section{Tool 5.1: Word clouds}

Word clouds are used to quickly identify major themes, concepts, and ideas by presenting them in a visual image, with the more commonly used terms in larger font sizes. There are multiple word cloud generators available online or through Microsoft Word. These are useful when it comes to portraying the prevalence and influence of actors or other key TMA elements.

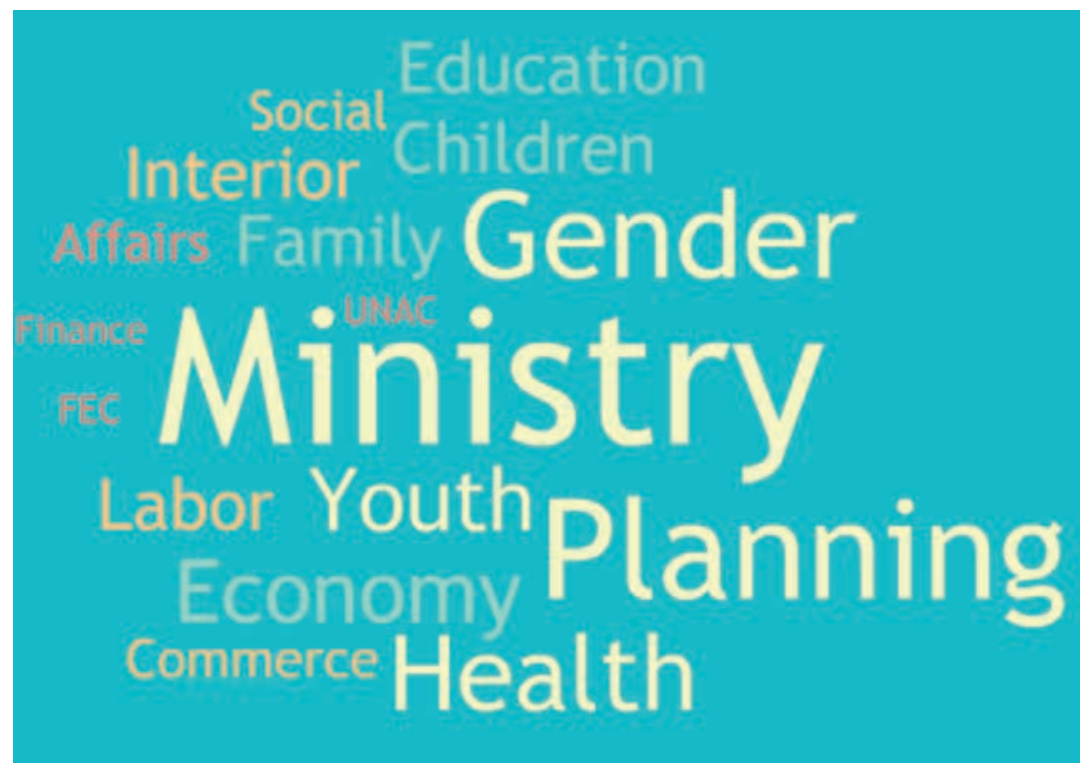

Figure A2. Word cloud demonstrating the frequent mention of government ministries during stakeholder interviews.

Figure A2 demonstrates the number of times the relevant ministries were mentioned as critical to future TMA efforts during stakeholder interviews. The larger the word, the more frequently the particular ministry was mentioned. Similar word clouds can be created to feature other TMA areas, such as contraceptive methods or major organizations active in a local market.

\section{Tool 5.2: Policy maps}

Policy mapping can help identify policies, actors, and relationships that may support or hinder your operation. Generally, relevant TMA policies and stakeholders are identified through a combination of desk review research and key informant interviews. For example, many line ministries have websites where they post national policies, strategies, and guidelines, as well as organizational charts that identify key personnel. Before creating a policy map, it is good practice to first conduct desk research to get a general assessment of the environment. Then hold interviews to collect data on TMA-related policies and fill gaps in knowledge, as well to increase the size of the stakeholder sample and identify other policymakers, influencers, and partners related to the topic at hand. Because policy mapping is generated from existing knowledge and sources, it is useful as a good first step to discover what the TMA environment theoretically looks like (see Figure A3). Radar maps 
(see Tool 5.3), and the more advanced network mapping (see Tool 5.4), which requires more resources and technical knowledge, are a more precise way of determining what the actual TMA environment looks like, and which stakeholders are most influential in reality.

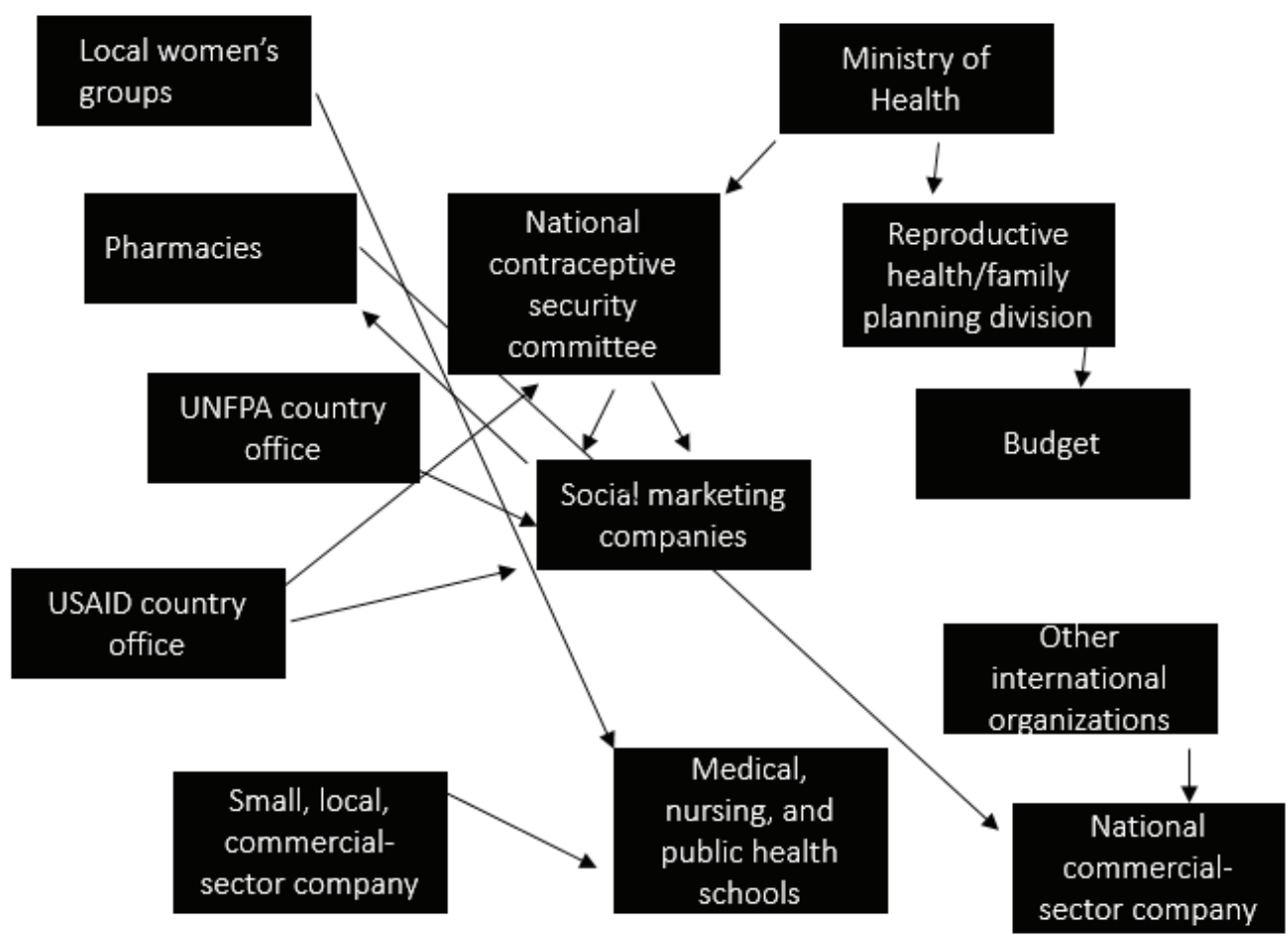

Figure A3. Sample map.

Tool 5.3: Radar maps

Radar maps are useful for visualizing the actors and organizations that exist in a country or area and the strength of the connections between them. They are created by taking quantitative data and using a computer spreadsheet (such as Microsoft Excel) to compute the data and create a visual representation. Using the data obtained from the key informant interviews (see Tool 4.4 for an interview guide), it is possible to create a radar map for the various stakeholders in a given market context. This can be done by using the responses to specific questions, in this case the sample questions for Tool 4.4 that ask respondents to rate various organizations and actors on their levels of awareness and support, to quantitatively rank the levels of influence, awareness, and support of various stakeholders in their country. With that data, it is then possible to begin populating a Microsoft Excel table.

To create a radar map using data collected from your TMA assessments, use the following instructions: 
- Select the range of data for which you would like to create a chart.

\begin{tabular}{|l|l|r|r|r|}
\hline \multicolumn{2}{|c|}{ A } & \multicolumn{2}{c|}{ B } & \multicolumn{2}{c|}{ D } \\
\hline 1 & Stakeholder & Influence Level & Awareness Level & Support Level \\
\hline 2 & PSI & 3 & 5 & 3 \\
\hline 3 & Ministry of Health & 5 & 2 & 2 \\
\hline 4 & PATH & 3 & 4 & 3 \\
\hline 5 & DFID & 3 & 3 & 4 \\
\hline 6 & MO Genre & 2 & 2 & 3 \\
\hline 7 & IPPF & 3 & 3.5 & 2 \\
\hline 8 & USAID & 4 & 3.75 & 5 \\
\hline 9 & UNFPA & 4 & 4 & 5 \\
\hline 10 & & & &
\end{tabular}

- Click Insert > Other Charts > Radar, and select the type of radar chart type.

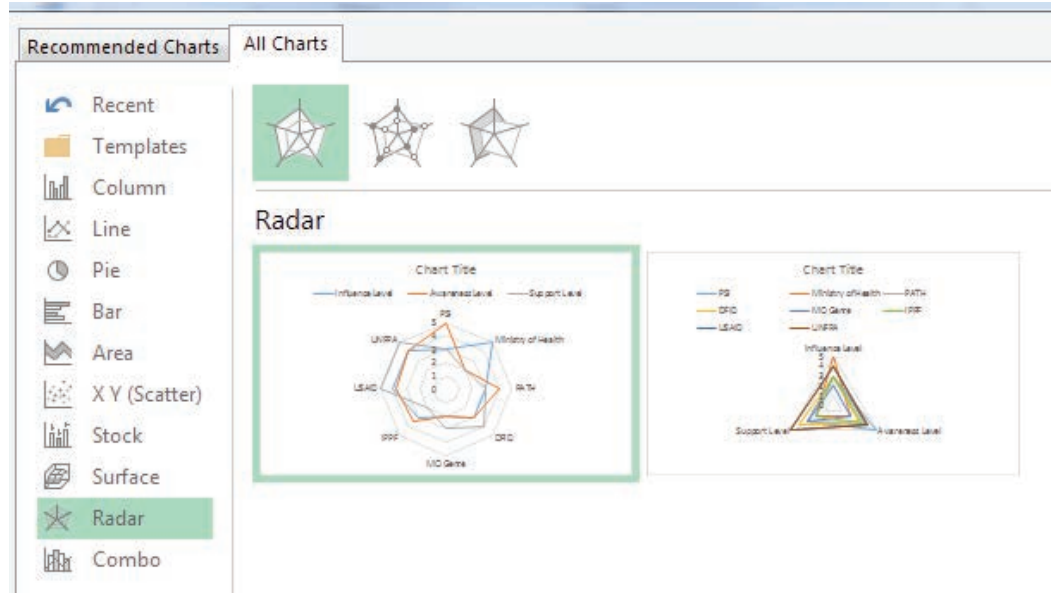

- Create the chart.

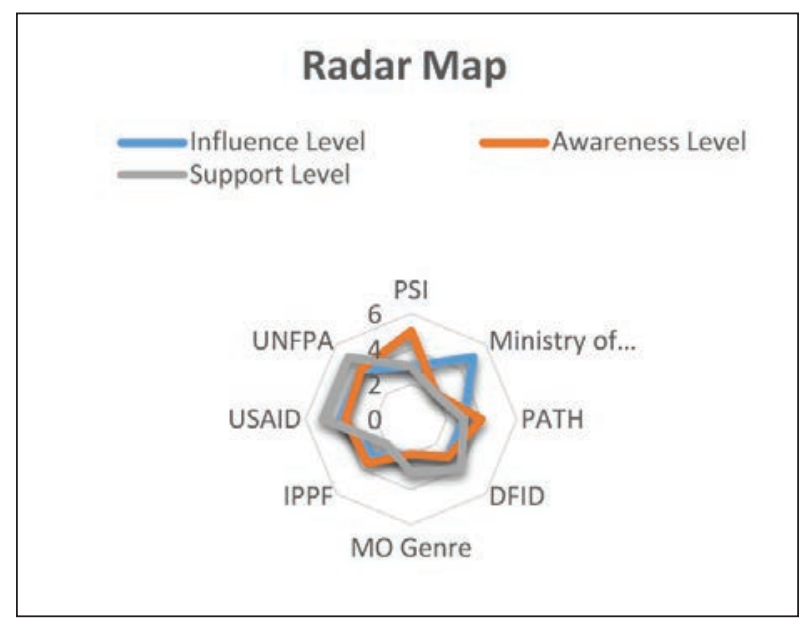


This radar map represents the quantitative level of various characteristics for each stakeholder (UNFPA, USAID, etc.). The stakeholders are listed around the edge, and the lines represent each characteristic and its level for each stakeholder, with the outside edge (5) being the strongest and the inside (0) being the weakest. The radar itself is just a background, in which to visualize those characteristics and their strengths. In this graphic, for example, the Ministry of Health has a high level of influence (5), but much lower levels of awareness and support.

While radar maps can be an effective way of understanding what a TMA situation looks like on the ground, these maps are not able to show the strength and extent of relationships with exact mathematical accuracy. A network map (Tool 5.4) is an advanced type of chart that shows the overall structure of a network, which can be useful for predicting the likelihood of policy change.

\section{Tool 5.4: Network maps}

A more advanced version of the radar map is the network map, which uses advanced software to visualize the specific relationships between organizations, as well as the strength of those associations. Like the radar map, these data are typically collected through in-person or online surveys. Unlike the radar map, which uses Microsoft Excel to generate useful but limited graphics, network mapping requires special social network analysis software that is capable of more advanced mathematical formulas and visual representations that give a better understanding of the TMA landscape. With complete data on all TMA actors, network analysis is able to predict the likelihood of policy change based on the observed structure of the TMA network, and can explain why some relationships exist and others do not.

For example, a TMA assessment led by PATH in Vietnam created a network map using data obtained from a survey of key stakeholders. The survey data was entered into Microsoft Excel, and the network map that resulted is shown in Figure A4.

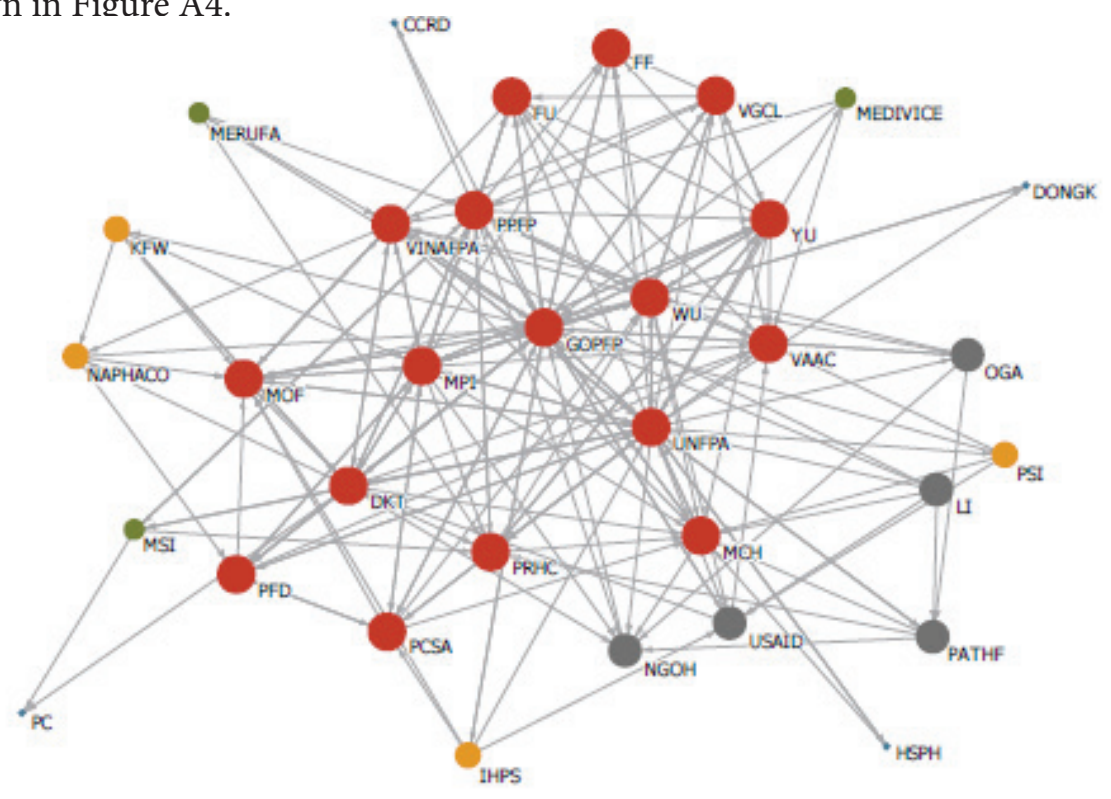

Figure A4. Sample network map created for a PATH TMA project in Vietnam.

Source: Source: Drake JK. Developing a Total Market Plan for Family Planning in Vietnam. Seattle: PATH; 2011. 
The graphic in Figure A4 highlights the centrality of the Vietnamese Government Office for Population and Family Planning and UNFPA to the FP network. A large red dot indicates that an organization is part of the most closely connected subgroup in the analysis; dots of other colors and sizes designate smaller and less closely connected subgroups. In this particular example, private-sector nonprofit groups including Marie Stopes International and Population Services International and commercial groups like Dongkuk, NAPHACO, MERUFA, and Medivice are found on the edges of the map, indicating that coordination could be improved.

For more information on network mapping, please consult the resources listed below. However, your organization may not have the software, the money to purchase this software, or the staff with the experience necessary to create these types of maps.

Suggestions for further reading about stakeholder and network mapping:

1. Brinkerhoff DW, Crosby BL. Managing Policy Reform: Concepts and Tools for Decision-Making in Developing and Transitioning Countries. Bloomfield, CT: Kumarian Press; 2002.

2. Dobel JP, Day A. A Note on Mapping: Understanding Who Can Influence Your Success. Seattle: The Electronic Hallway; 2005. Available at: http://ambounds.org/docs/334/Mapping\%20Article.pdf

\section{Tool 6: Sample Agenda for Stakeholder Dissemination Meeting and Sample Outline for Breakout Groups}

It is critical to share findings from the desk review research and the stakeholder interviews both with those who contributed to them and with others who may have an interest. A dissemination meeting or workshop is the best forum because it allows for exchange and idea generation among participants. Such a meeting is also a good opportunity for stakeholders to come together to validate information and identify next steps. When you share findings, be sure to present material, trends, or themes in a neutral and unbiased fashion. It is important for the stakeholders to understand that data may be incomplete or nonexistent and that ultimately many decisions are made in absence of data.

Tool 6.1: Sample agenda for stakeholder dissemination meetings

Date:

Venue:

Objectives:

- To share the key findings of stakeholder interviews and FP landscaping to a broad range of stakeholders.

- To review recommendations and clarify potential roles and coordination mechanisms for different FP actors in different sectors. 
- To identify data/evidence gaps that will help define the need and scope for market segmentation research and analysis.

- To discuss next steps by soliciting strategic input on how the findings can be applied to strengthen and expand TMA activities.

\section{Facilitators:}

\section{Proposed meeting agenda:}

\begin{tabular}{|c|c|c|}
\hline TIME & ACTIVITIES & PRESENTERS \\
\hline $8: 00-8: 10$ a.m. & Welcome of participants. & [Context-specific text] \\
\hline 8:10 - 8:30 a.m. & Introduction and review of meeting agenda and objectives. & [Context-specific text] \\
\hline $8: 30-10: 15$ a.m. & $\begin{array}{l}\text { Overview of TMA country landscaping assessment. } \\
\text { Broad objectives and assessment process. } \\
\text { TMA overview and conceptual framework. } \\
\text { Review of key findings from stakeholder interviews. } \\
\text { Conclusions and recommendations. } \\
\text { Questions and discussion. }\end{array}$ & [Context-specific text] \\
\hline 10:15 - 10:30 a.m. & Tea break. & [Context-specific text] \\
\hline 10:30 - 11:30 a.m. & $\begin{array}{l}\text { Next steps to promote a TMA. } \\
\text { Introduce small-group discussion exercise. } \\
\text { Divide into three groups by key thematic area. Select the } \\
\text { thematic areas that the majority of the stakeholders interviewed } \\
\text { mentioned as requiring urgent attention. For example: } \\
\text { - Coordination mechanisms. } \\
\text { - Market data collection and analysis. } \\
\text { - TMA advocacy. }\end{array}$ & [Context-specific text] \\
\hline $11: 30-12: 00$ noon & Report out to plenary and discussion. & $\begin{array}{l}\text { Discussion-group } \\
\text { leaders }\end{array}$ \\
\hline 12:00 - 12:30 p.m. & $\begin{array}{l}\text { Highlight significant themes and gauge potential for traction in } \\
\text { moving forward with key TMA-related scopes of work. } \\
\text { Wrap-up and closing: summarize recommended next steps for } \\
\text { TMA work. }\end{array}$ & [Context-specific text] \\
\hline
\end{tabular}


Tool 6.2: Sample outline for dissemination workshop breakout groups

The TMA assessment will identify the issues that are most popular and are thus the most useful to include in breakout-group sessions. The template below uses three sample topics to demonstrate a possible structure for these breakout sessions, but the groups and topics can easily be modified with whatever areas of concern your assessment has found to be most important.

\section{Sample outline for breakout group}

\section{Overarching question}

Within the three priority areas highlighted during the landscaping process, what are the most important activities to undertake immediately to promote a TMA for family planning and to begin to implement discrete TMA activities?

Sample priority areas:

- Establishing a TMA coordination mechanism.

- Identifying and filling key evidence and data gaps.

- TMA advocacy.

\section{Instructions}

Each group will review their specific objective and then discuss all of the suggested discussion questions in terms of their specific topic. The designated leader will lead the discussion, and each group should select a secretary/reporter who will record the reflections and recommended actions. The leader will jot down answers on chart paper and then present the main recommendations during the plenary. The following objectives and questions can be used to structure the discussion and to track key inputs/suggestions from the members of the breakout group.

\section{Example}

Sample priority area: Collecting and analyzing total market data.

\section{Objective}

To identify the most significant data gaps and most promising ideas for research to support FP TMA programming in the future.

\section{Discussion questions}

1. Given what you understand about TMA and what you have heard in the presentations and discussion today, what are the most significant evidence and/or data gaps that need to be addressed to support the development of a successful TMA plan? 


\section{Considerations for discussion:}

- Does high-quality market data already exist that is readily available and that can be used to support a TMA to support ongoing work to ensure equity, access, and quality? For example:

- Is it possible to gauge the size and composition of the FP private for-profit sector and to segment the market by the three main sectors (public, private nonprofit, and private for-profit)?

- Is data on potential/latent demand for [context-specific text] available?

- Do we have the data required to make projections on private-sector market growth?

- Is there data on willingness and ability to pay?

- Is data available on contraceptive expenditures by wealth quintile, broken out by sector and market segment?

2. Highlight missing data and rank by importance.

3. What are practical ways to fill these gaps?

4. How will the information gathered be used to design future TMA activities in [context-specific text]? Considerations for discussion:

- Can this data be used to improve the coordination between NGOs active in rural outreach and social marketing?

5. For other data gaps-those that were not chosen as immediate priorities-what is required to secure that data?

6. Can we identify existing mechanisms that can be used to gather the data?

Considerations for discussion:

- Availability of routine surveys or other data collection systems (e.g., Demographic and Health Survey, IMS Health). 


\section{Tool 7: How Participating in TMA Work Can Benefit the Commercial Contraceptive Sector-Pitch Sheet}

To be successful, a TMA must offer positive value to players in all sectors. While there has been increased interest in expanding public-private partnership opportunities, many governments, donors, and implementing partners have limited experience working with the commercial sector. As a result, the commercial sector tends to be left out of TMA discussions, and government actors struggle to find ways to effectively engage with them. Likewise, commercial-sector actors initially may fail to see how a TMA will help them achieve their goals and may be skeptical of the process. This presents serious challenges during the landscape assessment as well as during the development of a national total market approach plan. Addressing this disconnect requires focused attention by TMA planners and advocates. The following tool can be used to provide commercial-sector actors with a concrete rationale for why being involved in a TMA can be to their benefit. The rationale focuses on two important considerations from a commercial-sector perspective: access to useful market data and identification of new business opportunities.

\section{Pitch 1. Access to useful data and future market outlook.}

\section{BACKGROUND}

An important component in any TMA is the collection and analysis of contraceptive market data. TMA research typically includes consolidating and analyzing a wide range of data, such as estimating the market share of each sector, determining price points, listing different brands available in the market, and identifying sources of supply per population segment. A TMA also endeavors to clearly identify the preferences and profiles of key consumer segments. An important objective for TMA planners will be to highlight information about what these population segments want, so that each sector can better decide how to maximize their own comparative advantage.

A common complaint from the commercial sector (such as manufacturers, wholesalers and distributors) is that they end up competing with the government and with social marketing entities who receive donated commodities and offer them at either subsidized or no cost. Without understanding the role of market segmentation, this is perceived as an unfair advantage, given that commercial-sector entities are faced with a different set of priorities that need to be met in order to ensure their long-term financial viability. This point of contention is often exacerbated when market distortions occur due to free or subsidized products flooding the market. One reason this has happened in the past is that data are not routinely shared and estimates of need are based on inaccurate or incomplete information. Traditional approaches to forecasting have tended to ignore commercial sources of supply and are based more on need than on realistic assessments of actual use. In the absence of reliable data that show actual uptake of contraceptives at the retail or clinic level, there has been a tendency to use demographics to estimate how many contraceptives men and women will use. This approach tends to overestimate demand, and when governments and donors use this estimate of need as the basis for procurement decisions, it can result in flooding the market with free and/or subsidized product. Another potential consequence can be increased leakage from public-sector warehouses to commercial outlets. 


\begin{tabular}{|c|c|}
\hline $\begin{array}{l}\text { BENEFITS } \\
\text { TO THE } \\
\text { COMMERCIAL } \\
\text { SECTOR }\end{array}$ & 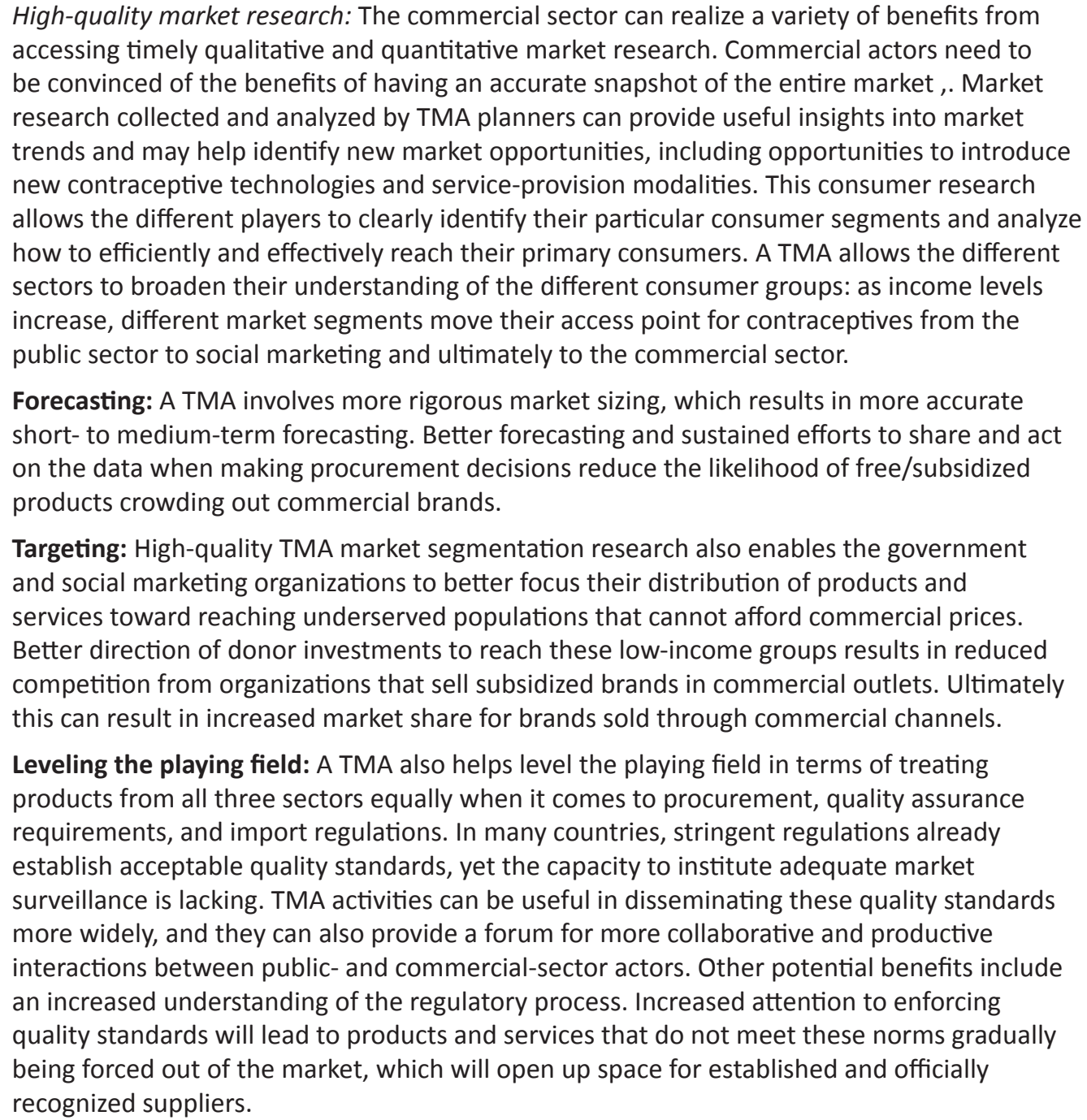 \\
\hline $\begin{array}{l}\text { POTENTIAL } \\
\text { PITFALLS AND } \\
\text { CONCERNS }\end{array}$ & $\begin{array}{l}\text { To capture the necessary data on the relative size of all three sectors, TMA planners ask } \\
\text { commercial partners to share sales information. Some commercial actors are hesitant to } \\
\text { provide this information, fearing that it may give competitors an unfair advantage. Some may } \\
\text { also have concerns about possible tax implications. } \\
\text { In the commercial sector, there is often a desire to maintain a distance from the public sector } \\
\text { to avoid undue government interference in day-to-day business practices. This concern is } \\
\text { based on the perception that providing government with additional information may result in } \\
\text { increased regulatory hurdles. }\end{array}$ \\
\hline
\end{tabular}




\begin{tabular}{|c|c|}
\hline $\begin{array}{l}\text { WAYS TO } \\
\text { MITIGATE } \\
\text { CONCERNS }\end{array}$ & $\begin{array}{l}\text { To allay fears that competitors will gain an edge or that companies will face other negative } \\
\text { consequences due to sharing sales data, it is important to point out that this information will } \\
\text { be aggregated by a reliable and trusted third party. This means that proprietary information, } \\
\text { such as sales volumes and/or pricing information provided by individual companies, will } \\
\text { remain confidential. } \\
\text { During data collection, all parties must be cognizant of the fact that there will be } \\
\text { understandable limits to the type and level of information commercial players can and are } \\
\text { willing to share. At a minimum, to complete the market sizing exercise annual sales volumes } \\
\text { will be needed. } \\
\text { Becoming a part of regulatory discussion will allow commercial-sector players to understand } \\
\text { the key issues more thoroughly and be prepared for any subsequent changes. }\end{array}$ \\
\hline $\begin{array}{l}\text { CONCRETE } \\
\text { EXAMPLES } \\
\text { AND } \\
\text { ILLUSTRATIVE } \\
\text { CASE STUDIES }\end{array}$ & $\begin{array}{l}\text { Market segmentation research and TMA work conducted in Honduras in } 2009 \text { provides a } \\
\text { good example of how TMA can influence focusing strategies. This research confirmed the } \\
\text { fact that the share of condoms distributed through the commercial sector was very low, } \\
\text { while large numbers of free and subsidized contraceptives were being accessed by middle- } \\
\text { and high-income groups. Based on this information, the government decided to reduce } \\
\text { the number of condoms available for free distribution in urban areas and instead focus on } \\
\text { distribution to rural populations. This resulted in significant increases in market share for } \\
\text { commercial suppliers, as more urban consumers shifted to purchasing branded commercial } \\
\text { condoms. } \\
\text { The Reproductive Health Supplies Coalition (RHSC) has been successful in reducing } \\
\text { information gaps and facilitating discussions with manufacturers on key issues such as } \\
\text { price, quality, production volumes, market entry, and registration. The RHSC has several } \\
\text { projects under way now that aim to better assess long-term market demand through better } \\
\text { consumption data. } \\
\text { There are also situations in which the different sectors agreed to develop, issue, and promote } \\
\text { a high-quality seal. A high-quality seal is perceived as an asset for legitimate producers and } \\
\text { distributors who want to bolster their market position, as well as for consumers who want to } \\
\text { be able to easily identify which products to trust. This strategy is currently being promoted by } \\
\text { PATH's Healthy Markets project in Vietnam. }\end{array}$ \\
\hline
\end{tabular}

* Brunner B, Merida M, Crosby D, Miles L. Revisiting a total market approach to contraceptive security in Honduras. Cases in Public Health Communication \& Marketing. 2014;8(suppl 1):S64-S85. 


\section{Pitch 2. Identification of new business opportunities.}

BACKGROUND
A TMA is intended to identify and support national and donor policies that aim to improve the overall environment for enabling FP.

For many contraceptive manufacturers, distributors, and health care franchises operating in low- and middle-income countries, the market is not perceived as offering high enough value to invest in. This is due to the fact that profit margins for FP products and services are generally low. Nonetheless, there are numerous examples in which public and social marketing sectors have been successful in building up the market and generating demand. Demand-side and social and behaviorial change activities carried out by NGOs increase knowledge and use of products. Consumers get used to paying and purchasing products at alternative delivery points, including drugstores and pharmacies. This primes the market for demand of commercial products in the present and future and increases overall product use and the CPR. It is not often well understood among key FP players that for social marketing, the long-term goal is to "crowd in" commercial players by building demand (via the "halo effect") and grow the overall market. Steadily increasing sales volumes of subsidized products and services can demonstrate the level of latent demand for contraception and may convince commercial firms to expand their investments in the market.

There are numerous examples in which donor-funded projects were developed with the express purpose of empowering commercial groups and incentivizing their active participation (several are cited below). Increasingly, governments turn to outsourcing to revamp their supply chain design, develop new information systems, or develop new strategies for ensuring products reach end users. 


\begin{tabular}{|c|c|}
\hline $\begin{array}{l}\text { BENEFITS } \\
\text { TO THE } \\
\text { COMMERCIAL } \\
\text { SECTOR }\end{array}$ & 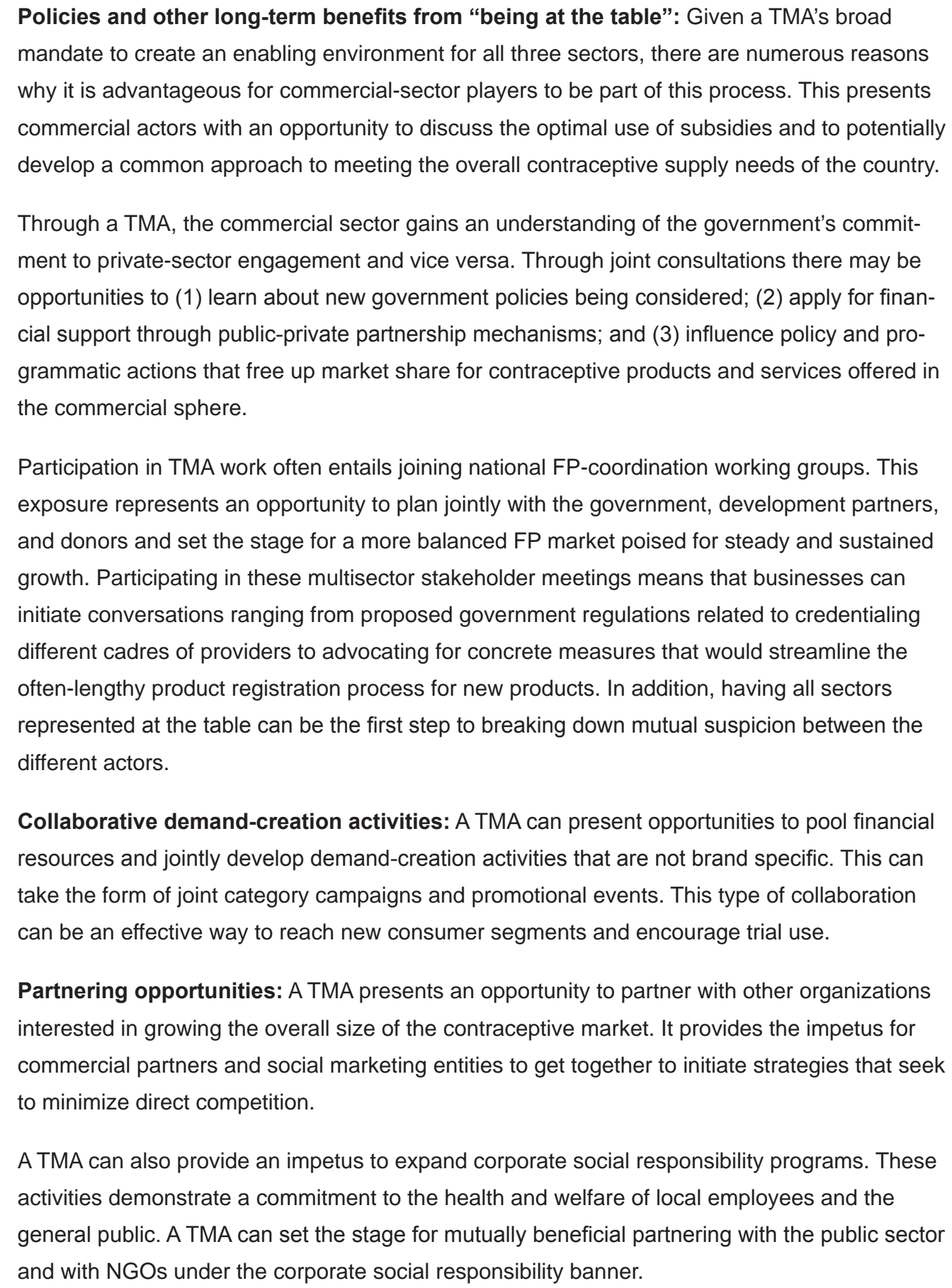 \\
\hline
\end{tabular}




\begin{tabular}{|c|c|}
\hline $\begin{array}{l}\text { POTENTIAL } \\
\text { PITFALLS AND } \\
\text { CONCERNS }\end{array}$ & $\begin{array}{l}\text { Some commercial-sector actors perceive TMA engagement as participating in unstructured } \\
\text { meetings without clear objectives, and in which politics drive the agenda. The public and pri- } \\
\text { vate sectors answer to different constituencies. This can translate into vastly different modes } \\
\text { of operation and organizational cultures. The commercial sector may see such engagement as } \\
\text { an unplanned and unbudgeted expense, which may be difficult to justify to its shareholders. }\end{array}$ \\
\hline $\begin{array}{l}\text { WAYS TO } \\
\text { MITIGATE } \\
\text { CONCERNS }\end{array}$ & $\begin{array}{l}\text { The commercial sector needs to be convinced that investing in a TMA will lead to financial } \\
\text { gains. The point can be made that developing a common approach and engaging in collabora- } \\
\text { tive activities with other actors in the contraceptive market is a cost-effective strategy. By work- } \\
\text { ing as a block, risks and costs are spread out. } \\
\text { There are also opportunities to join and support professional associations and local chapters } \\
\text { of chambers of commerce. Representatives from these groups can take on some of the more } \\
\text { tedious coordination responsibilities and provide advice regarding potential opportunities. } \\
\text { When organizing meetings with the commercial sector, prepare a well-defined agenda in ad- } \\
\text { vance that highlights clear short-term and long-term objectives. }\end{array}$ \\
\hline $\begin{array}{l}\text { EXAMPLES AND } \\
\text { LLUSTRATIVE } \\
\text { CASE STUDIES }\end{array}$ & $\begin{array}{l}\text { The Bayer/USAID Contraceptive Security Initiative is one example of a multisectoral TMA part- } \\
\text { nership. This project targets six sub-Saharan countries with the aim of expanding the range of } \\
\text { options for purchasing affordable oral contraceptives. USAID supports a range of marketing } \\
\text { costs, while Bayer has committed to distributing Microgynon Fe }{ }^{\circledR} \text { at a price where production } \\
\text { and distribution are fully covered and that is also in line with the financial resources of mid- } \\
\text { dle-income women. This means that supply and availability are controlled solely by demand in } \\
\text { the respective country and are independent of subsidies. } \\
\text { Another example of adopting a common approach that strengthens the overall FP environment } \\
\text { is PATH's Healthy Markets project in Vietnam. Under the umbrella of this project, three local } \\
\text { condom manufacturers signed memorandum of understanding agreements and confidentiality } \\
\text { disclosure agreements with the Healthy Markets project. The memorandums of understand- } \\
\text { ing secured a commitment from the manufacturers to supply a sufficient number of condoms } \\
\text { to meet the needs of the Vietnamese market, and particularly that of vulnerable populations. } \\
\text { The manufacturers also committed to supporting a range of Healthy Markets activities, such } \\
\text { as joining an advisory board, sharing information on production and sales, and maintaining } \\
\text { product quality standards. In return, Healthy Markets committed to support the manufacturers } \\
\text { with marketing and distribution expertise and provide aggregated market information to inform } \\
\text { company decisions on pricing, packaging, and distribution channels. Healthy Markets is also } \\
\text { tasked with helping the manufacturers connect with new distributors and buyers to ensure } \\
\text { sustainable sales. }\end{array}$ \\
\hline
\end{tabular}




\section{APPENDIX 2. GLOSSARY}

\section{Commercial health sector}

The commercial health sector is a subset of the private health sector and is synonymous with for-profit entities. The commercial health sector is used to distinguish for-profit from nonprofit entities.

\section{Government stewardship}

In government stewardship, the government takes a lead role in mobilizing and coordinating all sectors and stakeholders toward a goal, such as to improve family planning services. This includes government oversight to ensure the high quality, availability, and affordability of nonstate providers of family planning. Stewardship does not mean "control", however; it is important for multiple voices to inform TMA development and implementation.

\section{For-profit}

A for-profit health care company can earn a profit, which is defined as revenues in excess of expenses. A for-profit health care organization has wide discretion on how to spend its profit. This distinguishes it from a nonprofit organization, which can spend profits only on the purpose for which it was formed.

\section{Franchise}

A franchise is a commercial mechanism for replicating a successful business strategy. Key components generally include a common business format, a branded identity, and a quality assurance system. A franchise is a business arrangement whereby a franchisor develops a system of conducting an activity and provides franchisees with the "know-how" to conduct the activity. A franchise operation offers additional benefits, ranging from a defined and exclusive territory and the use of a common name to a full-fledged operational structure with centralized management services such as advertising, financial accounting, marketing, and procurement. In the case of health care service providers in a clinic franchise system, a network of private practitioners offers a uniform set of services at a predefined cost and standard of care.

\section{Market segmentation}

Market segmentation is the process of viewing diverse populations as divided into smaller subgroups (segments) that are similar in characteristics, needs, and likely responses to product marketing or service delivery efforts. Market segmentation looks at current patterns of demand and use of reproductive health commodities and services to find better, more efficient ways to meet existing demand or to increase demand.

\section{Nongovernmental}

A nongovernmental organization (NGO) is an organization or institution that is entirely or largely independent of any national government. Although an NGO can technically be a for-profit organization, the term is generally used to describe an organization whose primary goal is social and supports a public good. 


\section{Nonprofit}

A nonprofit health care provider does not have profit maximization as a goal. Instead, it uses all revenues available after normal operating expenses to accomplish its purpose. Although nonprofits are allowed to generate extra revenue, they must be retained by the organization for its self-preservation, expansion, or plans, and not released as profits or dividends. Many nonprofits use the model of a double bottom line because furthering their cause is a more important priority than making a profit, although both are needed to keep the organization sustainable. Nonprofit organizations involved in health care are typically NGOs, community- or faith-based organizations, or other charitable organizations.

\section{Private health sector}

The private health sector is a large and diverse community comprising both for-profit and nonprofit entities that lie outside the public health sector. The private sector includes a wide range of health sector entities, including individual private practitioners, clinics, hospitals, and laboratories and diagnostic facilities; nongovernmental organizations; faith-based organizations; shopkeepers and traditional healers; pharmacies; and pharmaceutical wholesalers, distributors, and manufacturers.

\section{Private provider network}

A private provider network is an affiliation of health service providers grouped together under an umbrella structure or parent organization. Networks may be organized according to a variety of arrangements. The details of the arrangements vary widely but often include monitoring by a parent organization and commitment by members to standards, high quality, a given service mix, and prices. Private provider networks include professional associations as well as franchises.

\section{Public-private partnership}

A public-private partnership is any explicit joint program or project involving both public and private collaboration. Public-private partnerships to provide health services and products can take the form of public-sector subsidies to the private sector. Public-sector government or development agencies can also contract with private service providers or producers and distributors of products and commodities.

\section{Social marketing}

Social marketing is the use of commercial marketing techniques to achieve a social objective. Social marketers combine product, price, place, and promotion to maximize product use by specific population groups. In the health arena, social marketing programs in the developing world traditionally have focused on increasing the availability and use of health products, such as contraceptives or insecticide-treated nets.

\section{Stakeholder analysis}

A stakeholder analysis includes honing a list of stakeholders to interview, finding the best tools for gathering information, and conducting interviews. Stakeholder analysis also includes analyzing the data gathered, using the information collected to update the desk review, and visiting providers and other outlets that distributing products such as contraceptives to better understand what is happening at the field level. 


\section{Targeting}

Targeting is a mechanism that directs scarce resources in a planned manner to achieve program goals equitably. It is focused on the identification and selection of certain groups, households, or individuals who have particular needs and then concentrating resources to ensure those groups receive the benefits.

\section{Total market approach}

A TMA leverages the comparative advantages of all market sectors to enhance equitable and sustainable family planning across market segments with government coordination and support. It is based on an understanding that meeting the diverse needs of different population segments equitably requires increased attention on coordinating across sectors.

\section{Total market initiative}

A total market initiative (TMI) is a project (or an activity within a project) that is funded specifically to implement total market activities such as conducting a market segmentation analysis and engaging stakeholders to develop a five-year contraceptive procurement forecast that incorporates historical data from all three sectors.

\section{TMA stakeholders}

TMA stakeholders are the organizations that play important roles in the implementation of a TMA. There are three types of stakeholders in a family planning TMA:

1. Government actors in the health sector and in other sectors, such as finance, planning, and drug and pharmaceutical regulatory agencies.

2. Development partners, such as United Nations agencies; bilateral agencies; NGOs focused on family planning; and social marketing, civil society, and faith-based organizations.

3. For-profit commercial sector agents, such as private practitioners, clinics, hospitals, pharmaceutical importers, wholesalers, distributors, and manufacturers. For-profit stakeholders may include professional associations, networks of distributors, large private health facilities or medical institutions, health care franchises, private insurers, and in-country manufacturers of family planning products.

\section{Universe of need}

The number of products or services needed to reach universal coverage in the market. Universe of need is an important indicator for measuring the size of the market, making decisions about distribution and pricing as well as providing insights about future market potential (e.g., potential profits). 


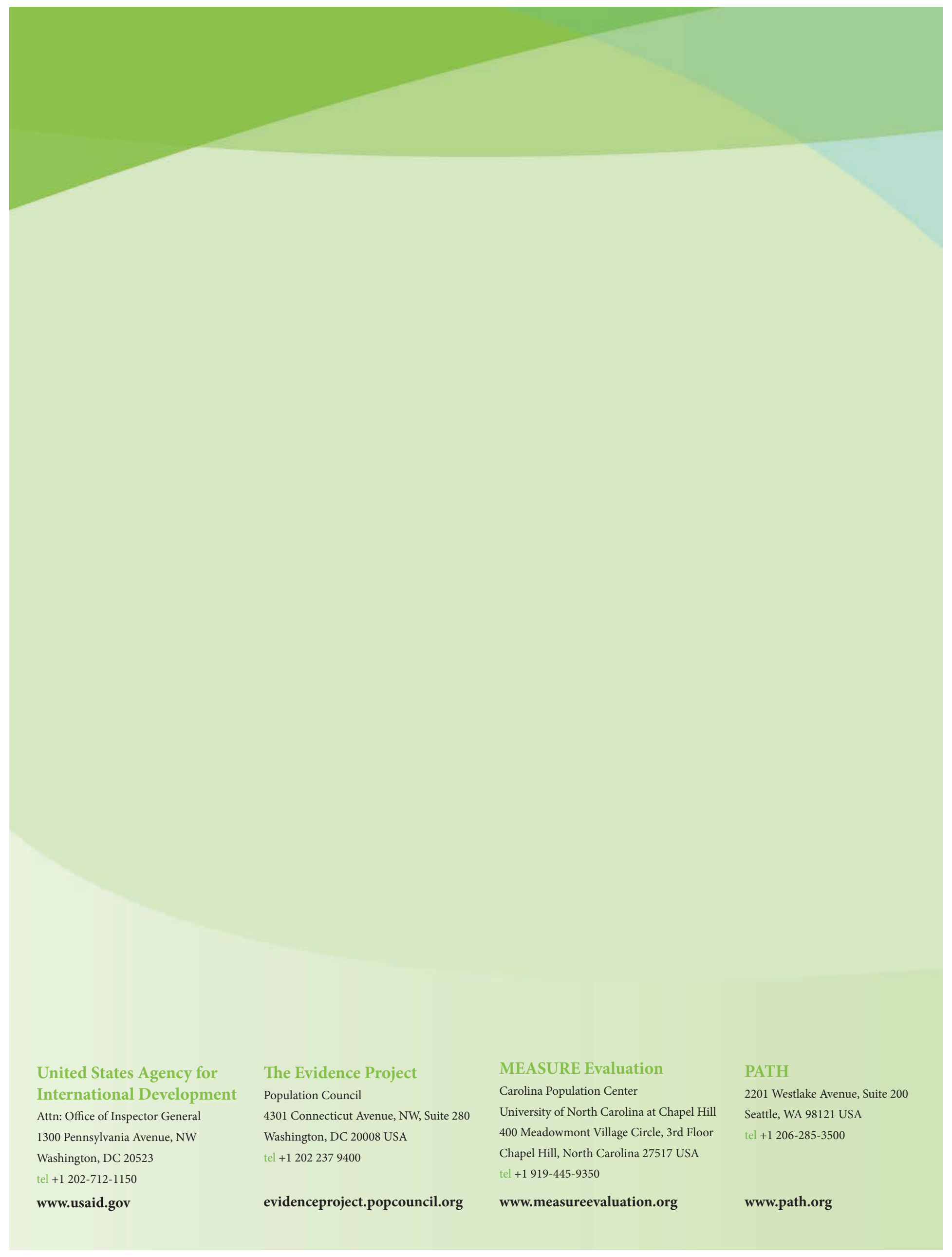

